\title{
CICLOS DE VIDA EN EMPRESAS DE SERVICIOS PÚBLICOS. LAS COMPAÑIIAS NORTEAMERICANAS Y BRITÁNICAS DE ELECTRICIDAD EN ARGENTINA, 1887-1950 *
}

NORMA SILVANA LANCIOTTI

Universidad Nacional de Rosario ${ }^{a}$

Consejo Nacional de Investigaciones Científicas y Técnicas

Life Cycles in Public Utility Companies. North American and British Electricity Companies in Argentina, 1887-1950

\begin{abstract}
During the first half of the 20th century, most electric utilities were owned by foreign companies in Latin America as well as in Argentina, where the electric system was managed by firms of different nationalities and types. After comparing the trajectories of the firms, the article explores the causes of the unsuccessful performance of the electric utilities managed by British and American companies in Argentina. The results show that the life-cycles of electric utility companies greatly diverged according to their style of management and financing, the entry into the market, and the level of capitalization and technology applied to electrical networks.
\end{abstract}

Keywords: economic history, transport, trade, energy, technology and other services, Latin America, micro-business history

JEL Classification: N76, N86

\footnotetext{
" Received 04/28/2008. Accepted 09/23/2008. Agradezco los comentarios de Eduardo Míguez

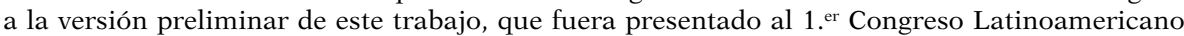
de Historia Económica (Montevideo, 2007); así como la orientación brindada por María Inés Barbero en la investigación que dio origen al mismo. Agradezco también las sugerencias de los evaluadores anónimos de la revista. La consulta de la documentación de las compañías holdings internacionales (Corporate Records, Historical Collection at Baker Library, HBS) fue posible gracias a una Beca Fulbright.

a Escuela de Economía, Facultad de Ciencias Económicas y Estadística, Bv. Oroño 1261, Rosario (2000), Argentina, nlanciot@unr.edu.ar.
} 


\section{RESUMEN}

Durante la primera mitad del siglo xx, los servicios eléctricos en Argentina y Latinoamérica fueron contratados con empresas de capital extranjero de diversos orígenes y formas de organización. A partir del análisis de las trayectorias de las compañías eléctricas en Argentina, el artículo evalúa los factores que incidieron negativamente en el desempeño de las empresas de electricidad de origen británico y norteamericano. Se establece que el desempeño económico y los ciclos de vida de estas empresas dependieron del estilo de gerenciamiento y la modalidad de financiación, así como del momento de entrada al mercado y de la tecnología aplicada a las redes eléctricas.

Palabras clave: historia económica, historia de empresas, compañías holding internacionales, empresas de electricidad, Argentina

\section{INTRODUCCIÓN}

Desde finales del siglo XIX hasta la segunda posguerra, la propiedad y gestión de los servicios públicos en Latinoamérica estuvo mayoritariamente a cargo de empresas de capital extranjero. En Argentina, empresas de origen británico, alemán, belga y norteamericano proveyeron los servicios de gas, electricidad y excepcionalmente de aguas corrientes. Organizadas como compañías autónomas, filiales de empresas multinacionales o empresas integradas a compañías holding, los ciclos de vida de estas empresas fueron divergentes en razón de los estilos de gerenciamiento y de financiación, el momento de entrada al mercado y el grado de capitalización y tecnología aplicado a las redes de servicios ${ }^{1}$.

Este artículo se propone analizar la evolución de las compañías de electricidad que operaron en Argentina entre 1890 y 1958, identificar las trayectorias frustradas y explicar los factores que incidieron negativamente en el desempeño de las empresas de electricidad de origen británico y norteamericano, cuyos ciclos de vida fueron breves o tuvieron resultados negativos. El análisis establece la relación entre los fracasos empresariales y las decisiones de inversión en diferentes fases del ciclo económico y tecnológico de la industria eléctrica.

Desde la perspectiva de la historia de empresas, el análisis propuesto requiere examinar tres cuestiones: la forma de organización de las empre-

${ }^{1}$ La gestión del sistema de aguas corrientes y cloacas estuvo a cargo del Estado argentino, salvo en las ciudades de Rosario y Bahía Blanca. Regalsky y Salerno (2008, pp. 120-127); Lanciotti (200/, pp. 112-113) Holding de servicios públicos refiere a las compañías que directa o indirectamente sean propietarias del 10 por cien de las acciones con voto de una compañía de servicios públicos o de otra compañía holding dentro de esta definición. United States. Securities and Exchange Commission (1952, p. 3). 
sas y sus capacidades gerenciales, el grado de desarrollo tecnológico del sector y las condiciones de las economías receptoras de la inversión extranjera. La primera cuestión se inscribe en el debate historiográfico sobre la evolución divergente de las multinacionales europeas y norteamericanas durante la primera mitad del siglo xx. Entre 1870 y 1914, las compañías legalmente autónomas -Free Standing Companies - constituyeron la modalidad de inversión externa más difundida en Europa, y especialmente en Gran Bretaña. Generalmente vinculadas a grupos de inversión de origen mercantil, estas compañías se caracterizaron por emprender actividades no asociadas a sus operaciones en el país de origen, diferenciándose de las multinacionales convencionales, cuyas subsidiarias desarrollaban ventajas competitivas adquiridas en las economías industrializadas ${ }^{2}$.

Esta última modalidad predominó en la inversión directa norteamericana gestionada mediante estructuras jerárquicas y coordinadas de empresas multinacionales y subsidiarias más competitivas, en términos chandlerianos. En respuesta, la historiografía británica de empresas optó por destacar el carácter industrial y empresarial de los grupos de inversión, desestimando la incidencia de la estructura organizativa en el fracaso de las empresas inglesas a favor de considerar factores estructurales como la menor competitividad de la economía británica de posguerra en áreas de reciente desarrollo tecnológico ${ }^{3}$.

Esta observación nos lleva al segundo eje de análisis, tal es, la relación entre el desarrollo tecnológico del servicio público y la forma de organización de las empresas. Wilkins (1988, p. 277) ha señalado que las compañías autónomas se concentraron en industrias cuya tecnología se había desarrollado en el siglo XIX, como las industrias ferroviaria y del agua, y evitaron los sectores de nueva tecnología. Por su parte, Hennart (1994, pp. 51-67) establece que los tipos no convencionales de inversión extranjera directa como las compañías holding y las compañías autónomas, representaron diferentes modalidades de internalización de los mercados de capital financiero, en lugar de la internalización de ventajas competitivas de las firmas. En su tipología de organizaciones basada en los mecanismos de transferencia de capital financiero según el grado de intermediación y coordinación, las free standing companies (FSC) constituyen organizaciones jerárquicas sin intermediación, adecuadas para financiar proyectos de riesgo en el extranjero, cuya escala de inversión fuera baja y la tecnología conocida. Aplicado al sector eléctrico, este planteo permite articular la forma de organización de las empresas con las condiciones financieras y tecnológicas de la industria. La escala de la inversión y el rápido cambio tecnológico de la industria eléctrica elevaron los costos de transacción, impulsando el des-

2 Wilkins (1988, pp. 259-270); Wilkins (1998, pp. 3-11).

${ }^{3}$ Corley (1994, pp. 86-87), Ch. Jones (1995, pp. 83-93); G. Jones (2000, pp. 338-353); Miller (1998, p. 243). 
arrollo de organizaciones jerárquicas con intermediación, como las compañías holding de electricidad.

La hipótesis de Hennart ha sido cuestionada por M. Casson (1994, pp. 95-99), para quien la clave de análisis de las compañías autónomas no reside en la distinción entre la internalización de capital y de ventajas competitivas, sino en la diferente naturaleza de las ventajas competitivas de la inversión directa en la industria manufacturera respecto de las industrias relacionadas con la propiedad, cuyos activos no pueden estandarizarse. La concentración de compañías autónomas en inversiones relacionadas con la propiedad de activos específicos en el exterior -i.e.: infraestructura de transportes, servicios públicos, minería, plantaciones o yacimientos petrolíferos- se debe a que en este tipo de industrias, la evaluación de los factores locales en la fase de instalación requiere de un juicio empresarial calificado. Los conocimientos específicos sobre localización, vías de transporte y relaciones con las dirigencias locales constituyeron la ventaja competitiva internalizada por las FSC. En una segunda fase, el conocimiento técnico de la actividad específica devino prioritario, por lo cual las compañías desarrollaron algunos proyectos y transfirieron otros según sus recursos disponibles. Así, la propiedad de activos en la región habría alentado la inversión en sectores de nueva tecnología, como el sistema eléctrico, y los grupos de inversión británicos habrían diversificado sus inversiones, manteniendo la estructura previa de las empresas. De esta situación, se derivaría el fracaso de las FSC en emprendimientos de nueva tecnología y elevado capital desde la primera posguerra.

Un tercer eje de discusión refiere a las condiciones de las economías receptoras de inversión extranjera: tamaño y naturaleza del mercado, políticas públicas y marcos regulatorios de la inversión, entre otros factores mencionados por Wilkins (1994, pp. 18-27). El impacto de las multinacionales en los países en desarrollo continúa siendo un tema poco analizado. El caso argentino asume especial relevancia, puesto que antes de la segunda guerra mundial, la inversión extranjera directa se dirigió mayoritariamente a países en desarrollo latinoamericanos y asiáticos; y Argentina ocupaba el cuarto lugar entre las economías receptoras de inversiones extranjeras en 1914 — después de Estados Unidos, Rusia y Canadá- y el sexto lugar en 1929. Por otra parte, los contados estudios sobre las empresas de servicios públicos antes de su nacionalización contrastan con el intenso debate sobre la actuación de las empresas extranjeras en el período de entreguerras ${ }^{4}$.

El análisis de las trayectorias frustradas de empresas eléctricas requiere considerar los criterios para definir el fracaso empresarial en este sector.

${ }^{4}$ Wilkins (1994, p. 21), Jones, Jones and Greenhill (1977), García Heras (1994), Lanciotti N. (200/); Regalsky y Salerno (2008). El estudio reciente de Hausman, Hertner y Wilkins sobre la evolución global del sistema eléctrico comprende la evaluación de las trayectorias fallidas. Hausman, Hertner and Wilkins (2008). 
Durante la fase expansiva de la electrificación, aun cuando la situación financiera de las empresas fuera crítica, difícilmente éstas declaraban la quiebra, puesto que sus activos fijos conformaban un capital fácilmente transferible a otra empresa. La tendencia a la formación de monopolios naturales en el sector habilitaba la recuperación de la inversión en explotaciones no rentables en la medida en que el activo de la empresa incluía la concesión para operar en un área definida. En las fases tempranas de desarrollo de los sistemas eléctricos, la inicial concurrencia de empresas frecuentemente dio paso a procesos de fusión y adquisición de empresas ${ }^{5}$.

¿Como medir entonces los fracasos? Un indicador puede ser la duración de las empresas en relación con las fases de desarrollo de los sistemas tecnológicos. Un segundo indicador es su rentabilidad promedio. La documentación disponible no permite analizar comparativamente los ingresos y utilidades de las compañías. No obstante, los datos sobre el capital y los dividendos de las sociedades anónimas de capital nacional o extranjero inscritas en Argentina, nos permite comparar la trayectoria de algunas empresas en forma más general, e identificar los fracasos ${ }^{6}$.

Un segundo interrogante remite a las causas del fracaso. En el sector analizado, las trayectorias fallidas pueden resultar de un cambio estructural de las condiciones económicas o tecnológicas, de cambios coyunturales motivados por determinadas políticas económicas o por la escasez de insumos, y finalmente, por problemas en la gestión y organización de las empresas. En otros términos, el desempeño de las empresas eléctricas depende de la disponibilidad y combinación de recursos técnicos y directivos, financieros, materiales e insumos - combustible, agua, materiales, maquinaria- y recursos relacionales/institucionales - la capacidad de acordar con el Estado y la adaptabilidad al cambio de políticas públicas.

En términos de Fridenson (2004, pp. 574-575), el análisis de los fracasos empresariales permite revisar los vínculos entre los mercados, las empresas, el Estado y las instituciones en diferentes períodos y tipos de mercado, evaluando la dependencia de cada uno de los mercados -financiero, de información, de productos, de insumos y de servicios- respecto a relaciones no mercantiles. En esta dirección, el último interrogante remite a las condiciones macroeconómicas en las cuales operaban estas empresas. Los

${ }^{5}$ Los sistemas tecnológicos incluyen artefactos físicos y organizaciones (firmas manufactureras, compañías de servicios, bancos de inversión, compañías holding). Las fases de su evolución - no siempre secuenciales - se definen por la actividad predominante: Invención, desarrollo, innovación, transferencia tecnológica, crecimiento, competencia y consolidación. Hughes (1987, pp. 51-57). La fusión y adquisición de empresas eléctricas se extendió hasta la segunda guerra mundial. Hausman, Hertner y Wilkins (2008, pp. 35-72).

${ }^{6}$ Entre la creación y cierre o transferencia de las empresas, se distinguen una serie de etapas que conforman el ciclo de vida de la firma. La evaluación comparada de los ciclos, las variaciones en la entrada, salida y crecimiento de las firmas contribuye a establecer relaciones entre las trayectorias de las empresas y los ciclos de negocios. Una perspectiva histórica de los ciclos de vida de las empresas en Moss y Jobert (1995). 
estudios generales de historia económica latinoamericana tienden a subrayar los procesos comunes a distintos países de la región. No obstante, las características del mercado, la evolución económica y las políticas públicas en Argentina difieren de lo observado para otros países latinoamericanos durante el período. Por tanto, estos aspectos deben ser integrados en el análisis del fracaso de empresas multinacionales, cuyas estrategias denotaban una perspectiva general de la región, no del todo atenta a ciertas condiciones específicas del país.

\section{LAS EMPRESAS ELÉCTRICAS DURANTE LA FASE INICIAL DE ELECTRIFICACIÓN EN ARGENTINA, 1887-1914}

La mayoría de las primeras empresas de servicios públicos que se instalaron en Argentina fueron compañías autónomas británicas vinculadas a los grupos de inversión establecidos en la región. Una actuación particularmente importante tuvo el grupo Morrison no sólo en la colocación de acciones en el mercado londinense, sino también en la formación de los directivos de las primeras empresas británicas en el país. En la fase inicial de operaciones, las compañías recibieron mayor participación de accionistas individuales; aunque el control accionario fuera ejercido por la compañía matriz del grupo, River Plate Trust, Loan \& Agency. El subsiguiente desarrollo de las redes demandó capital adicional, a partir de lo cual los accionistas institucionales aumentaron su participación ${ }^{7}$.

La compañía eléctrica más importante del grupo Morrison fue River Plate Electricity Company (Compañía de Electricidad del Río de la Plata), creada en 1889. La gestión para obtener la concesión no fue realizada por la compañía, sino por agentes ingleses radicados en Argentina, como Henry P. Boardman y Walter R. Cassels, que fueron contratados para construir una usina eléctrica y suministar energía en la ciudad de Rosario. Para acreditar su capacidad técnica, Cassels invocó su carácter de representante de Brush Electric Co. (EEUU), Davey Paxman y Cia. (Inglaterra) y Thomson-Houston International Electric Company (EEUU). Poco después, los agentes transfirieron el contrato a River Plate Electricity Co. La empresa tomó las concesiones obtenidas por Cassels en las ciudades de Buenos Aires, Rosario, La Plata y Tucumán. El 40 por cien de las acciones de la firma pertenecían a River Plate Trust, Loan \& Agency ${ }^{8}$.

${ }^{7}$ El grupo Morrison tenía participación accionaria en las siguientes empresas de servicios: Compañía de Tranvías de Buenos Aires y Belgrano, Compañía de Electricidad del Río de la Plata, Compañía de Aguas Corrientes de Rosario, Compañía de Cloacas de Rosario, Compañía de Aguas Corrientes de Montevideo, Compañía de Gas de Buenos Aires, Tranvías Ciudad de Buenos Aires, Compañía de Gas del Río de la Plata. Ch. Jones (1973, pp. 307-310); Jones, Jones y Greenhill (1977, pp. 77-94).

${ }_{8}$ Municipalidad de Rosario (1946, pp. 37-84). Entre los accionistas principales estaban F. Isaac, John Duncan, Charles Morrison y Frank Crisp. 
La gestión comenzó siendo muy accidentada. La firma no era gerenciada por un miembro del grupo como otras compañías en la región, sino por Walter Cassels. En Buenos Aires y Rosario, utilizaba una pequeña máquina Brush, insuficiente para generar energía, además de un deficiente sistema de lámpara de arco voltaico que provocó las protestas de los usuarios. Al cabo de doce meses, Cassels se retiró de Buenos Aires, reinstaló su máquina en La Plata y continuó operando en Rosario ${ }^{9}$.

Las condiciones del contrato de electricidad fueron diferentes a las pautadas con otras empresas del grupo. Mientras que las compañias de aguas corrientes y cloacas obtuvieron la provisión exclusiva de los servicios a largo plazo (setenta años), a tarifas en pesos oro; el convenio con la empresa de electricidad fijaba condiciones más imprecisas, no otorgaba exclusividad, limitaba la concesión a diez años y las tarifas máximas fueron fijadas en pesos moneda nacional. Estas diferencias entre concesiones eléctricas y de salubridad respondieron a disímiles etapas de desarrollo de la producción de los respectivos servicios. Los sistemas de aguas corrientes y cloacas habían alcanzado su madurez tecnológica en el siglo XIX, contando con prácticas de gestión estandarizadas hacia fines del siglo. Por el contrario, la industria eléctrica atravesaba una fase de innovación, el nivel de incertidumbre era elevado y los funcionarios municipales desconocían los aspectos básicos de la tecnología aplicada al servicio. Otra cuestión clave era que - a diferencia de las otras concesiones- las condiciones habían sido negociadas por agentes ajenos a la compañía. La decisión de River Plate Trust de invertir en el negocio eléctrico se basó en la confianza en el conocimiento específico de las operaciones manifestado por Cassels, y en su contacto con las autoridades locales ${ }^{10}$.

La fijación de tarifas en moneda nacional dio origen a sucesivos reclamos de la empresa para modificar el contrato. Inicialmente, los reclamos no tuvieron resultado, habida cuenta de que la crisis de 1890 generó una coyuntura desfavorable para la renegociación de los contratos. En los años de crisis, los gobiernos locales cuestionaron duramente la acción de las administraciones previas debido a las dificultades financieras de los municipios y a las denuncias de corrupción administrativa en el otorgamiento de concesiones. Por otra parte, el aumento del premio del oro - que llegó a su máximo en 1891- limitó el avance de las obras por cuanto la empresa percibía ingresos en moneda nacional devaluada, a la par que debía importar materiales a precios en alza para la construcción del sistema.

Las condiciones comenzaron a variar a mediados de la década. En 1896, Cassels renegoció el contrato con el Municipio de Rosario, que accedió a fijar tarifas máximas en pesos oro. A cambio, se estableció que cuando las utilidades excedieran el 10 por cien del capital invertido, el sobrante se dis-

\footnotetext{
9 Compañía Alemana Transatlántica de Electricidad (1910, pp. 9-16).

10 Sobre los sistemas de aguas y cloacas en Gran Bretaña, véase Hassan (1995, pp. 189-209).
} 
tribuiría por partes iguales entre municipio y empresa, y se definieron sanciones en caso de incumplimiento del contrato. Ese mismo año, los activos de la compañía fueron transferidos a una nueva empresa del grupo, la Compañía de Luz eléctrica y Tracción del Río de la Plata ${ }^{11}$.

La reorganización de la empresa tuvo por objetivo incorporar accionistas, ampliar el capital de inversión para modernizar las instalaciones en Buenos Aires y promover el desplazamiento de Walter Cassels, cuyos conocimientos sobre el negocio eléctrico habían mostrado ser limitados. Especialmente problemática para el grupo inversor, había resultado la autonomía con la cual se manejaba Cassels, quien desarrollaba emprendimientos paralelos y evitaba informar sobre sus operaciones al directorio de la compañía en Londres. En 1898, la dirección efectiva de la empresa fue asumida por Francis Chevallier Boutell, representante de River Plate Trust en el Río de la Plata, mientras que Frank Cassels — hermano de Walter- fue nombrado gerente ${ }^{12}$.

A pesar de los cambios en el paquete accionario y la recuperación del control de la gestión por parte de River Plate Trust, el servicio continuó siendo deficiente. Los informes de los inspectores señalaban el incumplimiento de las condiciones contractuales, identificando la aislación defectuosa de los conductores, insuficientes postes, luz inestable y de baja intensidad. Se convocó entonces a un tribunal arbitral que confirmó los reclamos del gobierno municipal, e instó a que la compañía cumpliera con el contrato. El proceso, que incluyó la apelación de la empresa, se extendió hasta $1902^{13}$.

Para entonces, el directorio resolvió liquidar la Compañía de Luz Eléctrica y Tracción del Río de la Plata, conservar la usina de Rosario y vender las restantes concesiones y activos. La estación Buenos Aires fue vendida a la Compañía Alemana Transatlántica de Electricidad (CATE) y la estación de La Plata fue transferida a una empresa británica no controlada por el grupo, bajo el nombre de River Plate Electricity Company. Los activos en Rosario pasaron a una nueva compañía del grupo Morrison, creada en 1902, The Rosario Electric Company Limited (Compañía Eléctrica de Rosario). La concesión eléctrica en Tucumán fue transferida a La Eléctrica del Norte, constituida en Buenos Aires en 1906, con aporte de capital del grupo ${ }^{14}$.

Durante este proceso, se produjeron cambios en el paquete accionario de la Compañía de Electricidad del Río de la Plata. En 1896, los accionistas de la empresa eran River Plate Trust, la compañía eléctrica Ferranti, los ban-

${ }^{11}$ La nueva empresa emitió acciones y obligaciones por 375.010 libras. Anuario Pillado de la deuda pública y sociedades anónimas establecidas en la República Argentina (1899, pp. 184185).

12 Ch. Jones (1973, pp. 145-149).

${ }_{13}$ Municipalidad de Rosario (1946, pp. 47-51).

14 Municipalidad de Rosario (1946, pp. 52-55). 
queros Kleinworts y numerosos inversores individuales. En 1902, RPTLA había disminuido su participación, incorporando nuevos inversores, entre ellos, la familia Guiness, Securities Investment Company, Omnium Investment Company, Government an General Investment Company y Otto Bemberg y Cía. El perfil institucional de los inversores se afianzó en 1903, cuando alrededor de veinte empresas poseían la mitad de las acciones ordinarias de la compañía ${ }^{15}$.

La reorganización de las empresas y algunas modificaciones a los convenios - en Rosario, se amplió la concesión a cincuenta años-generaron las condiciones para aumentar la inversión en el sistema. Las firmas comenzaron a obtener utilidades y a distribuir dividendos por primera vez. Desde 1906, la Compañía Eléctrica del Rosario distribuyó dividendos que oscilaron entre el 7 y el 8 por cien, similares a los obtenidos por otras compañías del grupo Morrison en esos años. En 1910, la firma fue vendida a la Société Electrique de Rosario (SER) por 518.000 libras ${ }^{16}$. La Compañía de Electricidad del Río de la Plata distribuyó dividendos levemente inferiores (6 por cien), mientras que la Eléctrica del Norte distribuyó dividendos cercanos al 8 por cien en los años previos a la primera guerra.

La modalidad de operación de la compañía alemana que operaba en la ciudad de Buenos Aires fue diferente a la recientemente descrita. Las empresas alemanas de electricidad en Europa y América del Sur se crearon como parte de la estrategia de las multinacionales eléctricas Siemens y AEG (Allgemeine Elektricitäts-Gesellschaft) de "crear su propio mercado, emprendiendo nuevos negocios». Estos emprendimientos fueron financiados por los bancos alemanes de inversión. AEG, el Deutsche Bank y el Berliner Handels-Gesellschaft aportaron el capital inicial de la Compañía Alemana Transatlántica de Electricidad (Deutsch Uberseeische ElektricitätsGesellschaft), conocida como CATE o DUEG ${ }^{17}$.

La CATE no era una multinacional convencional, puesto que su actividad no respondía a la extensión de ventajas competitivas desarrolladas en Alemania sino a la creación de mercados para sus productos, como se ha señalado. Tampoco era una free standing company: la empresa tenía su sede y consejo de administración en Berlín, pero también estableció sede y directorio en Buenos Aires, integrado por directivos locales y extranjeros, con el fin de expandirse hacia los países vecinos.

En 1901, la gerencia de la CATE-DUEG en Buenos Aires fue asumida por Mauro Herlitzka, un ingeniero italiano que trabajaba para AEG. La CATE emprendió entonces su expansión regional. Adquirió las usinas eléctricas de la Compañía de Electricidad del Río de la Plata y de la Primitiva Gas and

\footnotetext{
15 Ch. Jones (1973, pp. 173-174).

16 Monitor de Sociedades Anónimas, varios años; Municipalidad de Rosario (1946, pp. 56-59).

17 Hertner y Nelles (2007, p. 195). Hausman, Hertner y Wilkins (2008, pp. 99-100). Sobre la inversión directa y los bancos de inversión alemanes en Argentina, véase Young (1991).
} 
Electric Lighting of Buenos Aires. En 1905-1906, adquirió participación en las compañías tranviarias de Montevideo y Valparaíso; en Santiago de Chile, tomó el control de la Chilean Electric Tramway \& Light Co. En 1910, CATE era la única productora y distribuidora de electricidad en la ciudad de Buenos Aires, y controlaba cinco empresas de servicios públicos en la región ${ }^{18}$.

En sus comienzos, la CATE operaba con el sistema Edison de corriente continua con distribución trifásica. En 1900, terminó la primera parte de la usina de calle Paraguay, luego ampliada con nuevos grupos electrógenos. Pronto se introdujeron los cables subterráneos con conductor neutral y después de la adquisición de las pequeñas usinas de sus competidoras, CATE organizó un sistema de usinas y subusinas, colocando nuevas redes de cables de alta tensión y grupos turbogeneradores ${ }^{19}$.

A diferencia de las compañías inglesas que se crearon después de obtener la concesión en cada ciudad, CATE comenzó a operar en Buenos Aires sin tener más que una autorización para instalar las usinas y proveer electricidad. Que la inversión inicial se realizara sin contrato de concesión, manifiesta que las expectativas de crecimiento del mercado eran elevadas. La concesión por cincuenta años fue obtenida en 1907, cuando la empresa ya había adquirido todas las usinas y tenía el control del sistema en la ciudad capital. A continuación, CATE inició la construcción de la Usina de Dock Sud para corriente trifásica de alta tensión, habilitada en 1910. Para entonces, CATE era la empresa más capitalizada del país y contaba con el sistema más moderno y eficiente de Latinoamérica. La implementación del sistema de corriente alterna le brindaba amplios beneficios por economías a escala en el mayor mercado en términos de población e ingresos. Los dividendos repartidos entre 1906 y 1913 oscilaron entre el 9,5 y el 11 por cien ${ }^{20}$.

La Sociedad de Electricidad de Rosario (SER), sucesora de la Compañía Eléctrica del Rosario, se constituyó en Bruselas con un capital accionario de 17.500.000 francos belgas, en 1910. El 78 por cien del capital social fue integrado por tres empresas: la Société Financière de Transports et d'Entreprises Industrielles (SOFINA), la Société Centrale pour l'Industrie

18 CATE (DUEG), Informe anual, ejercicio 1906; CATE (1910, pp. 29-49). Herlitzka fue contratado inicialmente por Pirelli. Se trasladó luego a Berlín para trabajar en Siemens y finalmente fue contratado como ingeniero jefe de AEG, hasta que la empresa lo envió a Buenos Aires. Revista Electrotécnica (1933, p. 423).

19 Compañía Hispanoamericana de Electricidad (1927, pp. 3-6).

20 Compañía Alemana Transatlántica de Electricidad (1910, pp. 10-12, 29-40); CHADE (1927, pp. 3-6). La corriente alterna había sido una innovación introducida por Westinghouse a finales de los ochenta. Este sistema era adecuado para la transmisión de energía a larga distancia y para uso industrial, pero su difusión dependía de la creación de dispositivos como generadores, transformadores y conversores, que permitieran su interconexión con el sistema de corriente directa creado por Edison. La consolidación de un sistema universal provisto por generadores polifásicos estandarizados y vinculados por líneas de distribución de alto voltaje y bajo voltaje fue posterior al novecientos. Hughes (1987, p. 76). 
Electrique y la Compañía de Tranvías Eléctricos de Rosario. La SER fue la primera empresa eléctrica controlada por la compañía holding SOFINA en Argentina. El ingreso de SOFINA al mercado argentino se había producido poco antes, en 1906, con su participación en el consorcio europeo Compagnie Générale des Tramways de Buenos Aires, que adquirió el control de la británica Anglo Argentine Tramways en Buenos Aires ${ }^{21}$.

SOFINA había sido creada por la empresa eléctrica alemana Union Elektricitäts-Gesellschaft (UEG) en 1898, para desarrollar sistemas tranviarios. Su capital inicial ascendía a diez millones de francos belgas, aportado por el grupo alemán, el grupo belga integrado por la Banque Allard, Banque Cassel y Banque Jules Mathieu et fils y una participación menor de la norteamericana Thomson-Houston. Cuando la UEG se fusionó con AEG en 1903, esta última incrementó su participación accionaria en SOFINA. Bajo la dirección de Dannie Heineman - un ingeniero eléctrico norteamericano que dirigió la construcción de las redes tranviarias de las empresas de UEG en Europa-, la compañía transitó una primera fase expansiva centrada en la adquisición de empresas tranviarias en Europa Meridional y Sudamérica. Luego, la vinculación con AEG dio comienzo a su participación en el sector eléctrico, interviniendo en la creación de empresas eléctricas en Italia, Francia y Argentina ${ }^{22}$.

La SER se organizó como una compañía autónoma. Su Consejo de Administración en Bruselas estaba conformado por miembros del directorio de SOFINA, Victor Fris y Dannie Heineman entre ellos. Pero su operatoria y financiamiento no fueron típicos de una free standing company, sino equivalente a lo descrito para las compañías alemanas. Apenas constituida, la empresa duplicó su capital mediante la emisión de acciones de capital y de dividendo, que fueron adquiridas por sociedades industriales y financieras. El capital se invirtió en la construcción de una nueva usina, el reemplazo de las antiguas máquinas de vapor por turbinas de vapor, la instalación de calderas, turbogeneradores, turboalternadores y de una red subterránea de alta tensión para la ciudad de Rosario. La SER generó utilidades desde el comienzo de las operaciones y repartió dividendos del 12 por cien en promedio antes de la primera guerra. Para entonces, el sistema operado por la SER contaba con la misma tecnología que el sistema operado por la CATE ${ }^{23}$.

Estas empresas, cuyos directorios en Londres, Berlín y Bruselas ejercían el control de la gestión de las empresas operativas en Argentina, represen-

${ }^{21}$ SOFINA, S. A. (1930, s/p); García Heras (1994, pp. 18-19). La compañía de tranvías de Rosario pertenecía al grupo belga formado por las Compañías Anversoise de Tranways et d'Enterprises Electriques de Amberes, Mutuelle de Tramways y Banco Comptoir de la Bourse. Municipalidad de Rosario (1946, pp. 193-194). Sobre las inversiones belgas en el sector tranviario véase Martínez López (2003, pp. 59-77).

22 SOFINA, S. A. (1930, s/p); Brion y Moreau (2001, p. XVII). La UEG había sido fundada por Ludwig Loewe y Thomson-Houston Internacional. Hertner (1986, p. 128).

${ }^{23}$ Lanciotti (2008b). 
taron distintas variantes de la inversión directa extranjera en el sector eléctrico. Durante la fase inicial de electrificación, se crearon otras empresas en las que el capital extranjero ingresó como inversión de cartera. Nos referimos a un grupo de empresas registradas en Argentina, financiadas por inversores extranjeros y una participación menor de capital argentino, cuya gestión estuvo a cargo de directorios locales ${ }^{24}$.

Estas empresas estaban asociadas a dos consorcios de inversión. Uno de ellos fue integrado por inversores argentinos y británicos bajo el liderazgo de Mauro Herlitzka, quien fuera director-gerente de la CATE hasta 1910. Entre 1906 y 1914, el consorcio fundó ocho compañías de electricidad para operar en distintas provincias argentinas. Los directorios de las compañías estaban encabezados por Herlitzka, quien se encargó de negociar los términos de las concesiones con los gobiernos locales. La Compañía Anglo Argentina de Electricidad, creada en 1906, funcionaba como empresa matriz. Dos de las empresas fueron absorbidas por la Anglo Argentina poco después de constituidas, y otras dos empresas - Andina de Electricidad y La Eléctrica del Sud-eran subsidiarias de aquélla. Las restantes empresas del grupo fueron la Empresa de Luz y Fuerza de Mendoza, la Compañía General de Electricidad de Córdoba y la Empresa Eléctrica 9 de Julio.

La modalidad de operación y el estilo de financiamiento de estas sociedades fueron equivalentes al patrón de las compañías autónomas inglesas. El otorgamiento de la concesión precedió a la creación de las compañías en la mayoría de los casos, aunque dos de ellas fueron creadas sin precisar el área de servicio. Las compañías del grupo compartían sus directivos y las oficinas en Buenos Aires. La captación de capital se realizaba mediante la emisión de acciones y obligaciones ofrecidas al público y a entidades financieras que operaban en la plaza local. Así, en 1909 el Banco Francés del Río de la Plata intervino en la financiación de las empresas del grupo Herltizka; y el presidente del banco, Henry Py, integró los directorios de cuatro empresas del grupo ${ }^{25}$.

El capital de la Anglo Argentina se incrementó notoriamente entre 1910 y 1914 (cuadro 1). Esta capitalización no se aplicó al desarrollo tecnológico del sistema sino a adquirir usinas e incorporar compañías al grupo. El sistema estaba escasamente integrado y no contaba con tecnología reciente. Las empresas administraban pequeñas usinas, utilizando máquinas de vapor y corriente directa. En el período previo a la guerra, los resultados de estas compañías variaron según el mercado que servían. Por ejemplo, la Empresa de Luz y Fuerza de Mendoza evolucionó satisfac-

${ }^{24}$ Sobre los bancos de inversión y la creación de compañías holdings internacionales, véase Hausman, Hertner y Wilkins (2008, pp. 35-124). Sobre las Holdings eléctricas en Argentina, véase Lanciotti (2008).

${ }^{25}$ El Banco Francés del Río de la Plata había sido creado por la comunidad francesa en Argentina, con un aporte significativo de accionistas metropolitanos. Sobre Henry Py, M. Herlitzka y el Banco Francés del Río de la Plata, véase Regalsky (2001, p. 226). 


\begin{tabular}{|c|c|c|c|c|c|c|c|c|c|c|c|c|c|c|c|c|}
\hline$\infty$ & $\stackrel{\infty}{\stackrel{\infty}{=}}$ & & & $\begin{array}{l}0 \\
8 \\
8 \\
\text { i }\end{array}$ & & & 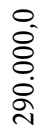 & & 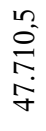 & & & & & & & $\begin{array}{l}\stackrel{0}{8} \\
8 \\
0 \\
\dot{8}\end{array}$ \\
\hline$\frac{a}{a}$ & ळ్ & & & & & $\begin{array}{l}\vec{a} \\
a \\
\text { aे }\end{array}$ & $\begin{array}{l}\infty \\
\stackrel{n}{n} \\
\stackrel{n}{n} \\
\stackrel{n}{2}\end{array}$ & 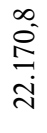 & 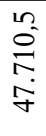 & & & $\begin{array}{l}0 \\
0 \\
\infty \\
\infty \\
\infty \\
\infty\end{array}$ & $\begin{array}{l}\stackrel{\circ}{+} \\
\stackrel{\sim}{\stackrel{2}{m}} \\
\stackrel{+}{*}\end{array}$ & & & $\begin{array}{l}\circ \\
8 \\
8 \\
\circ \\
8\end{array}$ \\
\hline 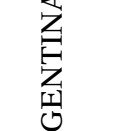 & $\stackrel{\widetilde{\Omega}}{2}$ & & & & & 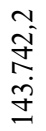 & \begin{tabular}{l} 
in \\
ô \\
\multirow{2}{0}{} \\
in
\end{tabular} & & $\begin{array}{l}\stackrel{n}{m} \\
\stackrel{m}{+} \\
\stackrel{1}{y}\end{array}$ & & & & $\begin{array}{l}0 \\
0 \\
\text { in } \\
\text { in }\end{array}$ & & & $\begin{array}{l}0 \\
\stackrel{-}{8} \\
\dot{8} \\
\infty\end{array}$ \\
\hline $\begin{array}{l}\alpha \\
4 \\
Z \\
1 \\
0\end{array}$ & ஜ̊ & & & & & $\begin{array}{l}\overrightarrow{1} \\
1 \\
\infty \\
0 \\
\dot{0} \\
\pm\end{array}$ & $\begin{array}{l}0 \\
\stackrel{0}{0} \\
\infty \\
\infty \\
\infty \\
m\end{array}$ & & $\begin{array}{l}\underset{1}{1} \\
\approx \\
0 \\
\infty \\
\infty\end{array}$ & 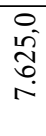 & $\begin{array}{l}\infty \\
\stackrel{\infty}{\sim} \\
\end{array}$ & 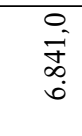 & $\begin{array}{l}0 \\
\stackrel{8}{8} \\
\text { in }\end{array}$ & $\begin{array}{l}0 \\
8 \\
8\end{array}$ & $\begin{array}{l}n \\
\text { an } \\
m \\
\text { in }\end{array}$ & 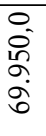 \\
\hline 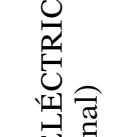 & $\stackrel{\infty}{2}$ & & & 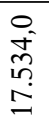 & & $\begin{array}{l}\tilde{2} \\
\infty \\
\check{\infty} \\
a\end{array}$ & $\begin{array}{l}0 \\
8 \\
8 \\
\text { i }\end{array}$ & & 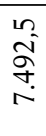 & $\begin{array}{l}0 \\
\stackrel{1}{2} \\
\text { ọ } \\
\end{array}$ & $\begin{array}{l}m \\
10 \\
\infty \\
0 \\
0 \\
\infty\end{array}$ & $\begin{array}{l}\text { nn } \\
\stackrel{5}{0} \\
\stackrel{+}{+}\end{array}$ & 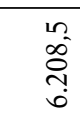 & $\begin{array}{l}0 \\
8 \\
\stackrel{+}{+}\end{array}$ & $\begin{array}{l}0 \\
\stackrel{8}{0} \\
\stackrel{n}{m}\end{array}$ & $\begin{array}{l}0 \\
8 \\
8 \\
0 \\
\dot{8}\end{array}$ \\
\hline 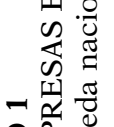 & ำ & & & & & 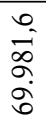 & $\begin{array}{l}-1 \\
\infty \\
0 \\
0 \\
-1\end{array}$ & & 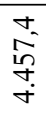 & 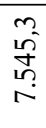 & $\begin{array}{l}m \\
\stackrel{n}{\Xi} \\
\dot{v}\end{array}$ & $\begin{array}{l}\stackrel{m}{2} \\
\stackrel{\sim}{*} \\
\stackrel{+}{+}\end{array}$ & $\begin{array}{l}0 \\
0 \\
0 \\
\stackrel{0}{1} \\
\end{array}$ & $\begin{array}{l}0 \\
8 \\
\dot{q}\end{array}$ & $\begin{array}{l}\tilde{\sigma} \\
\bar{\sigma}\end{array}$ & $\begin{array}{l}0 \\
8 \\
8 \\
\text { in } \\
m\end{array}$ \\
\hline 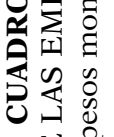 & ๙్ & & & $\begin{array}{l}0 \\
\dot{0} \\
\stackrel{2}{0} \\
\dot{m}\end{array}$ & 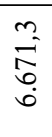 & 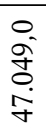 & $\begin{array}{l}+ \\
\infty \\
\aleph^{\circ}\end{array}$ & & $\begin{array}{l}\infty \\
\stackrel{+}{+} \\
\stackrel{\infty}{0}\end{array}$ & $\begin{array}{l}0 \\
\stackrel{8}{8} \\
\text { in }\end{array}$ & & $\begin{array}{l}0 \\
i n \\
0 \\
0 \\
+\end{array}$ & & $\begin{array}{l}\circ \\
8 \\
\dot{q}\end{array}$ & $\begin{array}{l}0 \\
\text { i. } \\
\stackrel{+}{+} \\
i\end{array}$ & $\begin{array}{l}\hat{\sigma} \\
\stackrel{\infty}{\infty} \\
\sigma^{2}\end{array}$ \\
\hline 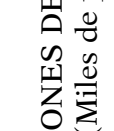 & $\frac{10}{2}$ & & & & 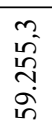 & & $\begin{array}{l}\infty \\
\tilde{\infty}^{-}\end{array}$ & & in & $\begin{array}{l}0 \\
0 \\
8 \\
i \\
i\end{array}$ & \begin{tabular}{l}
$n$ \\
\multirow{I}{*}{} \\
on \\
in
\end{tabular} & & $\begin{array}{l}0 \\
\text { in } \\
n \\
n \\
n\end{array}$ & $\begin{array}{l}\circ \\
8 \\
\dot{q}\end{array}$ & $\begin{array}{l}\circ \\
\stackrel{8}{8} \\
\stackrel{8}{+}\end{array}$ & $\begin{array}{l}0 \\
\stackrel{+}{+} \\
i \\
\sim\end{array}$ \\
\hline U & $\stackrel{\check{a}}{2}$ & & & & $\begin{array}{l}n \\
\stackrel{n}{n} \\
\infty \\
0\end{array}$ & & 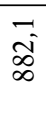 & $\begin{array}{l}\dot{v} \\
\dot{0} \\
\stackrel{m}{n}\end{array}$ & $\begin{array}{l}0 \\
0 \\
0 \\
0 \\
\end{array}$ & & in & $\begin{array}{l}m \\
0 \\
8 \\
\dot{0}\end{array}$ & $\begin{array}{l}n \\
\text { బू } \\
\text { in }\end{array}$ & & & $\begin{array}{l}\overrightarrow{\text { ô }} \\
\text { m. }\end{array}$ \\
\hline $\begin{array}{l}\lambda \\
\infty \\
y \\
Z \\
0\end{array}$ & 웅 & $\begin{array}{l}\infty \\
\text { i } \\
\infty \\
\infty \\
i\end{array}$ & $\begin{array}{l}+ \\
\stackrel{+}{+} \\
\text { a } \\
m\end{array}$ & $\begin{array}{l}a \\
\infty \\
n \\
n \\
+\end{array}$ & $\begin{array}{l}10 \\
0 \\
0 \\
0 \\
\infty \\
+\end{array}$ & & & $\begin{array}{l}0 \\
\dot{8} \\
\text { ¿े } \\
\text { in }\end{array}$ & 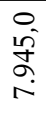 & $\stackrel{0}{\stackrel{0}{n}} \stackrel{\stackrel{n}{=}}{=}$ & No & $\begin{array}{l}0 \\
\stackrel{8}{8} \\
\dot{0}\end{array}$ & & & & \\
\hline 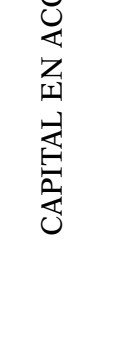 & 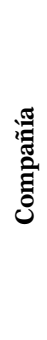 & 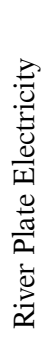 & 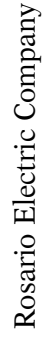 & 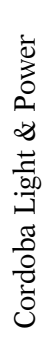 & 岁 & 焉 & 空 & $\overrightarrow{\mathrm{U}}$ & $\frac{x}{w}$ & 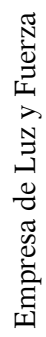 & 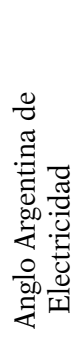 & 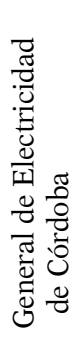 & 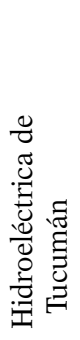 & 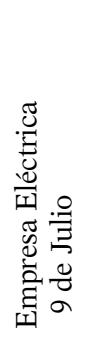 & 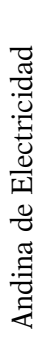 & 䆥 \\
\hline
\end{tabular}




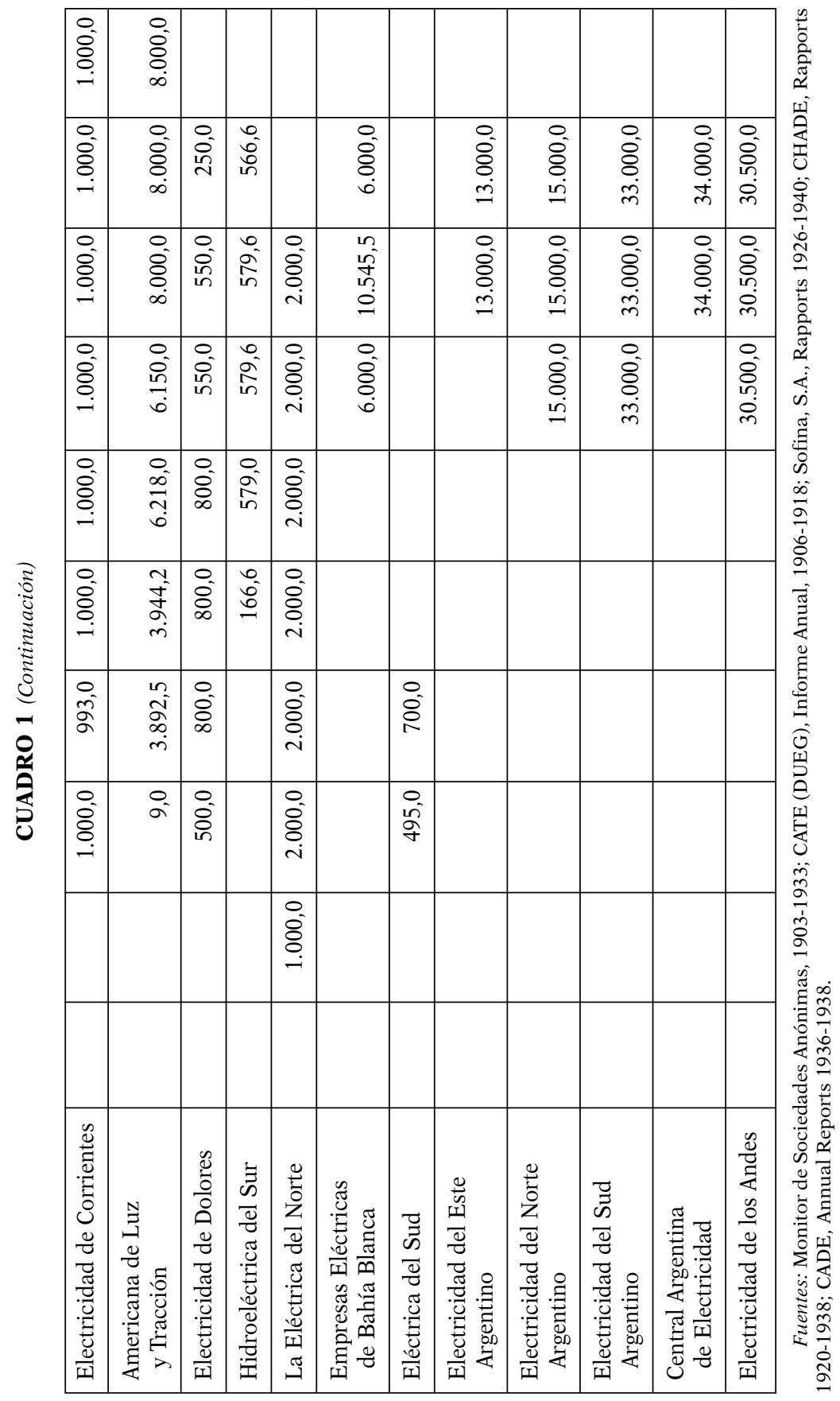


toriamente, distribuyendo dividendos del 10 por cien en 1910, cuando fue vendida a la CATE-DUEG. Los dividendos distribuidos por la Anglo Argentina de Electricidad alcanzaron el 8 por cien antes de la Gran guerra (cuadro 2).

El segundo trust financiero estuvo encabezado por Juan Carosio, un ingeniero italiano radicado en Argentina desde 1899. Carosio fue promotor y directivo de la Compañía de Electricidad de la Provincia de Buenos Aires, de la Eléctrica del Norte y de la Compañía General de Electricidad de Córdoba, creada en 1909, junto a Herlitzka y otros empresarios e inversores argentinos. En 1911, Juan Carosio, Ezio Belelli y Julio Poli constituyeron la Compañía Italo Argentina de Electricidad (CIADE) en la ciudad de Buenos Aires e iniciaron gestiones en Giarona para financiar el proyecto. Dos años después, se formó la compañía holding, que aportó el capital de la CIADE, Columbus AG für Elektrische Unternehmungen, con el concurso de la empresa eléctrica Brown Boveri, la compañía holding Motor, la Unión de Bancos Suizos, las empresas Pirelli y Franco Tosi, y un grupo de empresarios argentinos (grupo Devoto) ${ }^{26}$.

Asegurados el capital de inversión y la provisión de material eléctrico, se dio comienzo a la construcción del sistema de corriente alterna. La primera usina fue finalizada en 1914 y la segunda usina, dos años después. La potencia instalada de sus plantas se cuadriplicó entre 1916 y 1920. En 1917, la empresa comenzó a distribuir dividendos, que alcanzaron el 10 por cien en 1922 (cuadro 2) ${ }^{27}$.

El grupo incorporó tres nuevas empresas en 1914, Electricidad de Corrientes, Compañía Americana de luz y Tracción, y Electricidad de Dolores, en las cuales Columbus tenía el control accionario, y CIADE, el control directivo. Los empresarios italo-argentinos y argentinos del grupo Devoto, encabezados por Carosio, conformaron los directorios de las empresas ${ }^{28}$.

La forma de organización de la CIADE y sus empresas asociadas fue similar a la identificada para las empresas del grupo encabezado por M. Herlitzka. Ambos grupos comenzaron a operar en la misma coyuntura, alentados por el rápido crecimiento demográfico y económico de los centros urbanos. No obstante, el patrón de evolución tecnológica y la modalidad de financiamiento de la CIADE fue diferente al del grupo Herlitzka, a la vez que similar al estilo de CATE y SER, i.e: un acceso rápido al capital externo mediado por la participación de compañías holdings, una elevada

${ }^{26}$ Las holdings de Brown Boveri se fusionaron en Motor Columbus en la primera posguerra. Segreto (1994, pp. 163-68); Hausman, Hertner and Wilkins (2008, p. 101, 136). Sobre Carosio, véase Revista Electrotécnica (1933, p. 425).

${ }_{27}$ Compañía Italo Argentina de Electricidad (1931), Monitor de Sociedades Anónimas, varios años.

${ }^{28}$ Monitor de Sociedades Anónimas, varios años. Sobre el grupo Devoto, integrado por Carosio, véase Barbero (1990, pp. 267-240). 


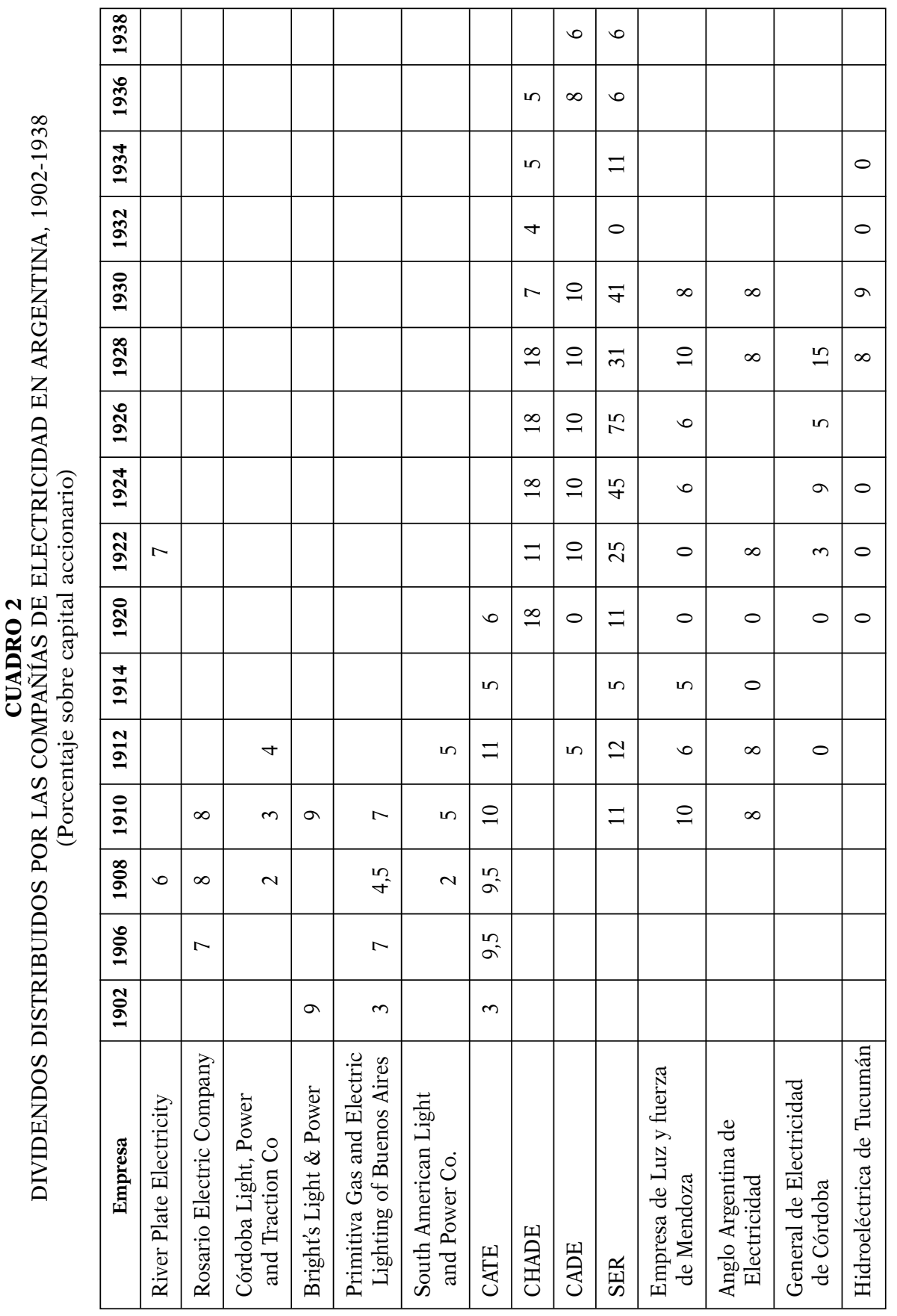


CICLOS DE VIDA EN EMPRESAS DE SERVICIOS PÚBLICOS. LAS COMPAÑÍAS...

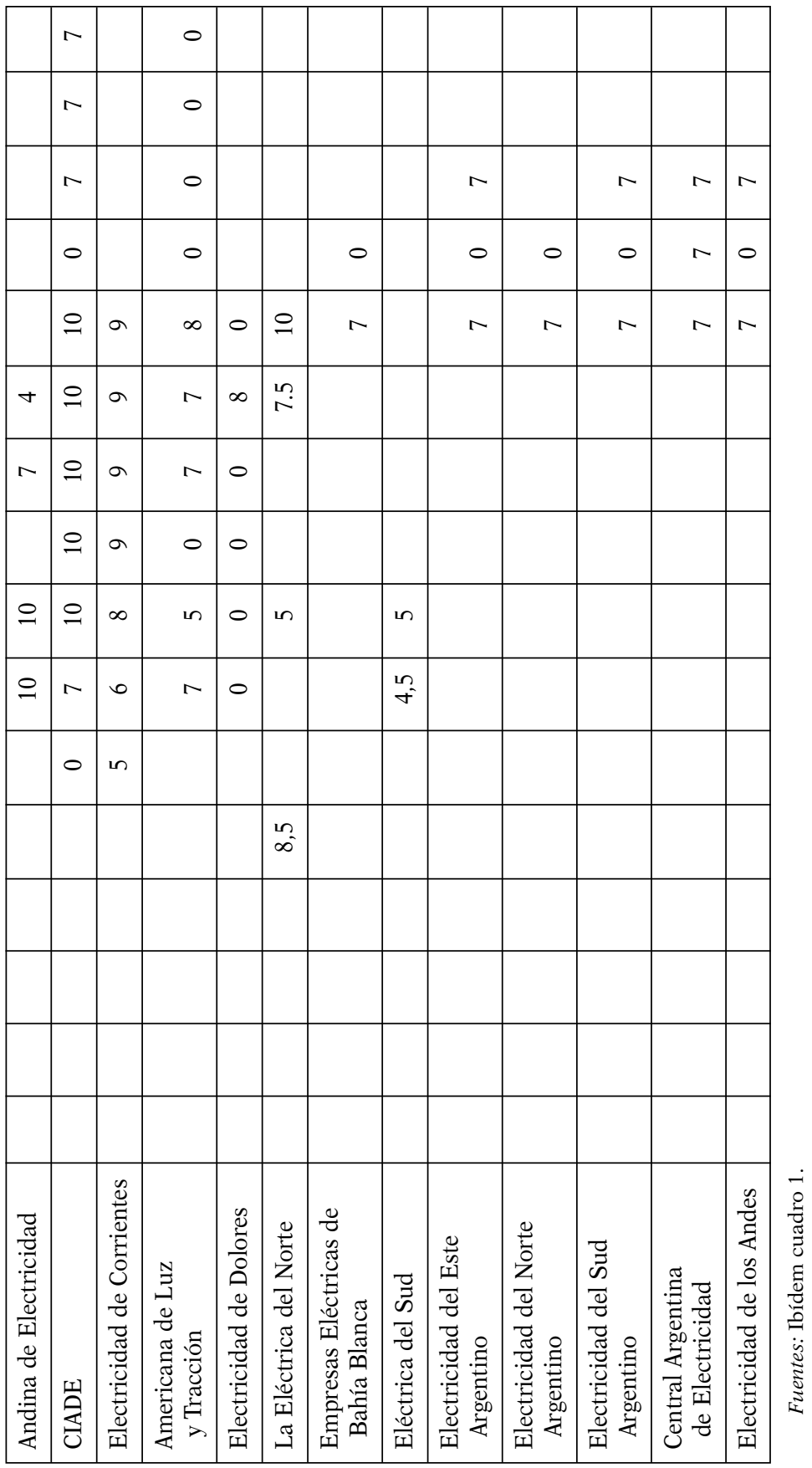


inversión inicial y la rápida incorporación de tecnología para el desarrollo de las redes ${ }^{29}$.

Las trayectorias brevemente expuestas nos permiten realizar algunas consideraciones. Entre el novecientos y la primera guerra mundial, la estructura de las compañías eléctricas se modificó. La concentración del sector dio lugar a la creación de estructuras integradas jerárquicamente entre compañías de distinto origen y forma de organización. La excepción está representada por las compañías autónomas inglesas, la mayoría de las cuales fue adquirida por empresas alemanas y belgas durante ese período. Las compañías inglesas que no fueron vendidas, como Córdoba Light, Power and Traction, Bright's Light \& Power Ltd., South American Light and Power Co., y Compañía de Electricidad del Río de la Plata (usina La Plata) no registraron cambios en su organización, en su patrón de evolución tecnológica ni en su estilo de financiamiento.

El proceso de integración y coordinación de las empresas fue paralelo a la configuración de sistemas regionales sólo en el área pampeana más poblada del país. Los sistemas del área pampeana estaban controlados por empresas integradas y coordinadas jerárquicamente por dos compañías vinculadas entre sí: CATE (DUEG) y SOFINA. En el resto del país, las empresas eléctricas también desarrollaron estructuras organizativas integradas, pero no se formaron sistemas eléctricos regionales. Las empresas operaban en regiones alejadas, con mercados limitados, mantuvieron el sistema de corriente directa, sin redes de subusinas y estaciones transformadoras. El desarrollo desigual de los sistemas implicó notorias diferencias en los costos y beneficios derivados de las economías a escala, que se hicieron visibles en la fase expansiva del consumo eléctrico durante los años veinte.

En los años previos a la guerra, la capacidad instalada alcanzaba a cubrir la demanda de los mercados pequeños y en crecimiento de las ciudades del interior. Por esta razón, las compañías que allí operaban pudieron obtener beneficios aceptables sin necesidad de ampliar el capital de inversión en proporción elevada. Dadas estas condiciones, las free standing companies inglesas produjeron utilidades equivalentes o levemente inferiores a las de otras compañías, crecieron poco pero sostenidamente y produjeron dividendos promedio aceptables. Esta situación era sustentable para empresas que operaban en mercados limitados sin intención de expandirse.

En los centros urbanos de elevado crecimiento demográfico, la opción de estas empresas era capitalizarse o vender. El financiamiento de las empresas británicas y anglo argentinas que operaban en Buenos Aires, Rosario y Mendoza se basaba en la emisión de acciones y de obligaciones

${ }^{29}$ Herlitzka y Carosio tenía un perfil similar. Ambos eran ingenieros italianos arribados al país en el cambio de siglo, con experiencia en la gestión de instalaciones de redes eléctricas en Europa. Dada la escasez de recursos técnicos y gerenciales, la formación y el origen propiciaron la rápida inserción de ambos en la comunidad empresarial de Buenos Aires. 
en el mercado londinense, captando numerosos capitalistas individuales y algunas empresas. Bajo esta modalidad, obtener los capitales necesarios para una elevada inversión inicial requería un lapso de tiempo. Esto implicaba mayores costos de transacción en comparación con el estilo de financiamiento de las compañías holdings, que podían reunir un elevado capital para sus proyectos de electrificación en menor tiempo y con bajos costos. Siguiendo la hipótesis de Hennart, la creación de compañías holdings representó un cambio en los mecanismos de transferencia de capital y en la modalidad de financiación de las empresas eléctricas. El desplazamiento de mecanismos de acceso al capital mediante organizaciones coordinadas por los grupos de inversión y con baja intermediación como las free standing companies, a favor del desarrollo de organizaciones jerárquicas con alto grado de intermediación, como lo eran las holdings eléctricas transnacionales, terminó por limitar las opciones de las empresas eléctricas inglesas y anglo-argentinas.

El cambio operado entre 1900 y 1914 no sólo refiere a los mecanismos de transferencia de capital, o en otros términos, al estilo de financiamiento, sino también a la configuración de redes regionales eficientes. La coordinación jerárquica de los recursos gerenciales, financieros y técnicos para la producción y distribución de los bienes en sistemas de red, generaba una baja en los costos operativos y de transacción, a la par que potenciaba el aprovechamiento de las economías a escala. La alternancia de un elenco limitado de ingenieros formados en el exterior en los directorios de distintas empresas argentinas y extranjeras constituye una señal inequívoca de la escasez de recursos gerenciales y técnicos especializados en electricidad en Argentina. La competencia entre las empresas por estos recursos escasos dio lugar a las conductas oportunistas de los directivos y gerentes de las empresas extranjeras, como se observa en el caso de Cassels. Pero además las bajas barreras de entrada durante la fase inicial de electrificación alentaban los emprendimientos paralelos de los gerentes de las compañías extranjeras dando origen a problemas de agencia, como sucedió en los casos de Cassels y de Herlitzka. Las dificultades de la Compañía de Electricidad del Río de la Plata en los primeros años son ilustrativas de esta cuestión.

Retomando el planteo de Casson, se observa que la creación de las compañías eléctricas inglesas fue el resultado de la extensión de las ventajas competitivas de los grupos inversores en industrias relacionadas con la propiedad. Los directivos del grupo Morrison - que operaba en Argentina desde los 1870s - contaban con un conocimiento específico relativo a las condiciones geográficas, económicas y políticas de la región, que fundamentó la decisión de invertir en el sistema eléctrico. Pero la gestión de las compañías fue delegada en agentes que mostraban tener un conocimiento específico sobre la industria eléctrica, constituyendo una de las posibles variantes adoptadas por las free standing companies. 
El fracaso de la gestión de Cassels hizo que el grupo británico retomara el control administrativo de la Compañía de Electricidad del Río de la Plata. Una vez reorganizada la compañía, la evaluación de las condiciones del mercado argentino realizada por el directorio del grupo resultó en distintas decisiones. La gestión del servicio en Buenos Aires requería una elevada inversión en capital y recursos gerenciales y técnicos que el grupo no tenía, de modo que la transferencia a la DUEG fue la opción lógica. La decisión de conservar la empresa en Rosario dependió de dos factores. Como el grupo controlaba las empresas de cloacas y aguas de la ciudad, mantener la empresa eléctrica resultaba menos oneroso puesto que las tres empresas compartían las oficinas y los recursos administrativos. En segundo lugar, las expectativas de crecimiento del mercado rosarino eran auspiciosas en 1902, aun cuando la empresa no hubiera generado utilidades por los conflictos ya explicados. Una inversión moderada en el sistema luego de lograr un nuevo acuerdo con el gobierno local prometía generar utilidades satisfactorias, distribuir dividendos y revalorizar las acciones de la compañía, abriendo la posibilidad de una venta futura en mejores condiciones. Esto es lo que efectivamente sucedió.

A partir de lo evaluado hasta aquí, podemos decir que en la fase inicial de la electrificación cuando el mercado no imponía elevadas barreras de entrada —no todas las empresas operaban bajo concesión y además las concesiones no garantizaban exclusividad-, la organización de las compañías dependió del estilo del financiamiento y de las vías de acceso a los recursos gerenciales y técnicos más que a la nacionalidad de la compañía o al origen del capital. Por otra parte, exceptuando a la compañía alemana antes de la guerra, el capital de las compañías holdings y consorcios de inversión que controlaban las acciones de las empresas operativas no provenía de un único país. Esta observación se aplica a las empresas controladas por el consorcio encabezado por Herlitzka, por el grupo italo-suizo-argentino y por SOFINA. La expansión de los sistemas eléctricos estuvo tempranamente asociada a la conformación de holdings internacionales con sede en Suiza o Bélgica, cuyos capitales, directorios y equipos técnicos provenían de distintos países.

El estilo de financiación y la modalidad operativa de las empresas vinculadas a los grupos Herliztska y Carosio era diferente, aunque la organización de las compañías fuera similar. La participación de Columbus en las empresas del grupo italo-argentino implicó la incorporación de mayor inversión y tecnología, incrementando las economías a escala. Un segundo factor refiere al mercado en el que operaban las empresas. El rápido crecimiento urbano del área litoral pampeana atrajo más capitales, y por ende mejor tecnología, incentivando la renovación de equipamiento y la introducción de la corriente alterna. Como resultado, las empresas de baja tecnología que operaban en las mayores aglomeraciones urbanas fueron pronto transferidas; mientras que en los centros menos poblados, las empresas 
tendieron a adoptar una política de inversión más conservadora, dilatando la renovación de equipamiento y la extensión de las redes.

\section{LA EVOLUCIÓN DE LAS EMPRESAS DURANTE LA EXPANSIÓN DEL SISTEMA ELÉCTRICO, 1915-1929}

Después de la primera guerra mundial, se inició un período de crecimiento económico durante el cual la estructura de las empresas del sector se mantuvo estable. Entre 1915 y 1927 no se crearon nuevas empresas eléctricas. El único cambio significativo fue la retirada de las empresas alemanas. La derrota alemana en la primera guerra mundial y la pérdida de activos en el extranjero complicó la situación de los bancos de inversión que habían financiado la expansión de las multinacionales eléctricas, y AEG debió transferir el control accionario de sus empresas en Sudamérica a SOFINA. SOFINA asumió entonces la gestión técnica y administrativa de la CATE (DUEG) y de sus subsidiarias, para lo cual creó en 1920 una nueva compañía con sede en España, la Compañía Hispanoamericana de Electricidad (CHADE). El capital de la CHADE fue integrado por bancos y empresas eléctricas españolas, belgas, suizas, francesas y alemanas ${ }^{30}$.

La transferencia no representó cambios en la estructura de las empresas operativas en Argentina, que se adaptaba adecuadamente a la estructura de las subsidiarias de SOFINA en América y Europa. Las empresas controladas por SOFINA estaban integradas por país, y en la mayoría de los casos, eran coordinadas jerárquicamente a través de compañías holding con sede en Bruselas, como también por compañías con sede en el país donde operaban las empresas. Pero además, las subsidiarias del trust belga tenían participación accionaria cruzada entre sí. En Argentina, las empresas subsidiarias de la CATE pasaron a ser subsidiarias de la CHADE. Bajo el control de SOFINA, la CHADE consolidó su papel como holding de otras empresas localizadas no sólo en el Cono Sur, sino en el continente europeo. Hacia 1930, la CHADE tenía participación accionaria en varias empresas, entre las cuales se contaban la Gesellschaft für Elektrische Unternehmungen (Gesfürel), la Société d'electricité de la Région de Malmédy (SERMA) y la Société Internationale d'Énergie Hydro-électrique (SIDRO). Esta última, a su vez controlaba a Barcelona Traction Light and Power Company, y a las empresas de SOFINA en México ${ }^{31}$.

${ }^{30}$ Sobre la transferencia de DUEG: Hausman, Hertner and Wilkins (2008, p. 135). Entre los accionistas españoles de la CHADE, se encontraban el Banco Hispano Colonial, el Banco de Vizcaya, el Banco Urquijo y la SA Arnus Garí. AEG mantuvo una participación minoritaria en la empresa. La CHADE absorbió además las empresas de DUEG en Uruguay. CHADE (1920, pp. 714). Al mismo tiempo, SOFINA recibió un nuevo aporte de capital belga, americano, inglés y francés.

${ }^{31}$ SOFINA (1926, p. 32); (1929, p. 38). 
Durante los años veinte, los ingresos y las utilidades de las empresas eléctricas en Argentina se incrementaron significativamente. La prosperidad alcanzaba no sólo a las empresas altamente capitalizadas del área pampeana, sino también a aquellas que operaban en las capitales provinciales o en pequeñas ciudades de la provincia de Buenos Aires. Desde mediados de la década, las compañías incrementaron el capital accionario, crearon empresas subsidiarias y adquirieron otras, con el objetivo de desarrollar los sistemas regionales.

La CHADE habilitó una nueva usina en 1929 y consolidó su control en la ciudad y provincia de Buenos Aires, con la adquisición de la Compañía de Electricidad del Río de la Plata (La Plata) y de la Compañía de Electricidad de la Provincia de Buenos Aires (CEP), que compró al consorcio Herlitzka. Hacia 1930, las usinas de la CHADE suministraban energía a tres millones y medio de habitantes en un área de 12.000 kilómetros cuadrados.

La CIADE obtuvo nuevas concesiones en los partidos de Avellaneda, Lomas de Zamora y Quilmes entre 1926 y 1928, lo cual demandó nuevos capitales de inversión y la construcción de otra usina de gran capacidad. Entre 1920 y 1930, la CIADE aumentó su capital integrado de 9.873 .000 a 69.950.000 pesos y duplicó la capacidad instalada de las usinas. En 1928, el grupo italo-suizo-argentino adquirió la empresa inglesa South American Light and Power Company, que pasó a denominarse Empresas Eléctricas de Bahía Blanca. El mismo año, la SER adquirió la Compañía de Luz y Fuerza de Rosario ${ }^{32}$.

En estos casos, el nivel de utilidades no sólo permitió distribuir dividendos satisfactorios, como se observa en el cuadro 2, sino también reinvertir una proporción significativa de las ganancias y aumentar las reservas de capital de las firmas. Por otra parte, las empresas controladas por el consorcio Herlitzka, también tuvieron una evolución económica satisfactoria. El grupo comenzó entonces a invertir en la instalación del sistema de corriente alterna en su mercado más importante: la ciudad y provincia de Córdoba.

La expansión de la industria eléctrica produjo una reorganización de las holding internacionales a fines de la década del veinte. Las empresas controladas por Motor Columbus en Argentina fueron transferidas a una nueva compañía en 1929, la Société Suisse-Américaine d'Electricité (SSAE), con sede en Zurich, que además del aporte de Motor Columbus, recibió capital de bancos norteamericanos. Un proceso aún más acentuado de expansión e internacionalización experimentó SOFINA. En 1928, con el nombre de Trust Financier de Transports et d'Entreprises Industrielles se constituyó una nueva SOFINA, con el aporte de 62 entidades financieras de origen belga,

32 Compañía Italo Argentina de Electricidad (1931); Société Suisse-Americaine D’electricité; Annual Reports, 1929-1932; Compañía Italo Argentina de Electricidad (1930); SOFINA (1929, p. 26). 
norteamericano, británico, holandés, francés, alemán, español, suizo italiano, húngaro y luxemburgués ${ }^{33}$.

El aumento de la inversión americana en el exterior no sólo se concretó mediante su participación en las holdings eléctricas europeas, sino también por la inversión directa en sistemas eléctricos de América Latina. En este contexto, las empresas norteamericanas ingresaron al mercado eléctrico argentino. Entre 1928 y 1932, American \& Foreign Power Co., una holding registrada en Maine, adquirió empresas eléctricas en once provincias argentinas. La firma había sido creada en 1923 por Electric Bond \& Share - una compañía holding controlada por la multinacional norteamericana General Electric Co. - para operar empresas de electricidad, gas y tranvías en América Latina. Entre 1924 y 1929, Foreign Power tomó el control de compañías en Ecuador, Colombia, Brasil, Venezuela, Costa Rica, Chile, México y finalmente Argentina ${ }^{34}$.

En su primer informe anual, los directivos de American \& Foreign Power explicaban que el éxito de las empresas coordinadas por compañías holding de electricidad en el mercado norteamericano, se debía a que esta estructura generaba menores costos, mejores servicios al público y una mayor seguridad para los inversores que las compañías operando por separado. Aunque las empresas estuvieran dispersas geográficamente, actuando en forma conjunta podían adquirir materiales en grandes cantidades, obtener mejores precios y emplear un equipo técnico común de especialistas. El informe también destacaba la facilidad de acceso al capital y los menores costos financieros asociados a dicha estructura ${ }^{35}$.

En este marco, la compañía norteamericana adquirió las empresas eléctricas inglesas que continuaban operando en Argentina, como la Compañía de Luz y Fuerza Motriz de Córdoba y Bright's Light \& Power Ltd; así como la totalidad de las empresas del consorcio Herlitzka: Compañía General de Electricidad de Córdoba, Compañía Hidroeléctrica de Tucumán, la Compañía Anglo Argentina de Electricidad y sus subsidiarias, la Andina de Electricidad y La Eléctrica del Sud ${ }^{36}$.

Según sus directivos, el obstáculo central para la expansión de American \& Foreign Power en Latinoamérica eran las «leyes anticuadas basadas en antiguas prácticas». El comentario aludía a la disparidad de concesiones y contratos entre las empresas adquiridas y las respectivas autoridades, comparada con el marco regulatorio relativamente homogéneo en los Estados

${ }_{33}$ Société Suisse-Americaine d'Electricité, Annual Reports, 1929-32; SOFINA, S. A. (1930, s/p).

${ }^{34}$ Wilkins (1974, pp. 122-137); American \& Foreign Power Company Inc., Annual Reports, 1924-1932; Hausman y Neufeld (1997, p. 47). Sobre la inversión directa norteamericana en la Argentina: Barbero (2004, pp. 201-222) y Lluch (2007).

35 American \& Foreign Power Company Inc. (1924, p. 1).

${ }^{36}$ Bright's Light \& Power y Córdoba Light, Power \& Traction habían sido transferidas a Atlas Light \& Power, una holding británica constituida en 1926. Tres años después, Atlas las vendió a la firma norteamericana. Hausman, Hertner and Wilkins (2008, p. 165); Solveira (2007). 
Unidos. De modo que en 1929, la compañía fijó como prioridad la renegociación de las relaciones contractuales con las autoridades para garantizar la inversión necesaria sin riesgo para los accionistas, y ampliar la capacidad instalada, reconstruir sistemas de distribución y expandir las ventas ${ }^{37}$.

El directorio identificó un segundo problema. En la mayoría de las concesiones, el sistema no había sido desarrollado para proveer un servicio que permitiera maximizar el factor de carga, lo que implicaba una utilización ineficiente de las instalaciones. Se señalaba además que los esquemas tarifarios vigentes basados en tasas únicas para distintas clases de servicio resultaban inadecuados para promover el aumento del consumo tal como lo disponían las estructuras modernas basadas en tarifas regresivas. Como solución, se propuso la reorganización de las empresas operativas para financiar mejoras y ampliaciones de las usinas a bajo costo, así como la implementación de planes de inversión para construir plantas de gran capacidad y sistemas de transmisión y distribución que hicieran razonable provisión del desenvolvimiento futuro ${ }^{38}$.

El diagnóstico de los directivos de American \& Foreign Power era correcto. Tal como hemos señalado, en Argentina la compañía adquirió empresas que producían utilidades aceptables, sin haber desarrollado sistemas tecnológicos integrados a nivel regional que maximizaran los beneficios de las economías a escala. Las antiguas compañías inglesas y las empresas integradas al consorcio Herlitzka no habían implementado sistemas de corriente alterna ni expandido la capacidad instalada, aún cuando las concesiones habían producido utilidades crecientes en los años veinte. En consecuencia la potencia instalada de las empresas de este grupo era limitada en comparación con las empresas de los grupos restantes (cuadro 3).

El estilo de financiamiento y la modalidad de operación de estas empresas no se habían modificado frente a los cambios en el mercado. Por ejemplo, entre 1920 y 1928, el capital de la británica Compañía de Luz y Fuerza Motriz de Córdoba había aumentado 27 por cien, y su capacidad instalada, sólo un 17 por cien. La Compañía General de Electricidad de Córdoba había construido dos pequeñas usinas hidráulicas de las cuatro acordadas con el gobierno y una planta termoeléctrica de las dos que debía construir. Aún cuando en 1927 se habían reemplazado las máquinas de vapor por generadores, la potencia continuaba siendo baja ${ }^{39}$.

37 American \& Foreign Power Company (1924, pp. 2-7). American \& Foreign Power Company Inc. (1929, pp. 7-8).

${ }^{38}$ American \& Foreign Power Company Inc. (1929, pp. 7-8).

39 Solveira (2007); Solveira (2006, pp. 11-13). 
CUADRO 3

POTENCIA INSTALADA DE LAS EMPRESAS ELÉCTRICAS (Kw)

\begin{tabular}{|c|c|c|c|c|c|c|c|}
\hline & \multicolumn{2}{|c|}{$\begin{array}{c}\text { Ciudad y provincia } \\
\text { de Córdoba }\end{array}$} & $\begin{array}{c}\text { Rosario } \\
\text { y sur de } \\
\text { Santa Fe }\end{array}$ & \multicolumn{3}{|c|}{ Ciudad y Provincia de Buenos Aires } \\
\cline { 2 - 8 } & $\begin{array}{c}\text { Córdoba } \\
\text { Light, } \\
\text { Power and } \\
\text { Traction }\end{array}$ & $\begin{array}{c}\text { General de } \\
\text { Electricidad } \\
\text { de Córdoba }\end{array}$ & SER & CIADE & CHADE & CADE & CEP \\
1911 & 4.760 & 1.850 & 18.000 & & & & \\
1921 & 9.560 & 2.400 & 28.000 & 86.350 & 125.190 & & \\
1926 & 11.560 & 2.840 & 42.800 & 113.450 & & & \\
1929 & 11.280 & 6.100 & 56.800 & 163.400 & 490.500 & 44.356 & 26.132 \\
1932 & 13.280 & 8.700 & 56.800 & 208.850 & 514.911 & 92.450 & 45.383 \\
\hline
\end{tabular}

Fuentes: Solveira (2006); Municipalidad de Rosario (1946); Compañía Italo Argentina de Electricidad (1931); SOFINA, Annual Reports, 1929-1932.

\section{ENTRE LA CRISIS DEL TREINTA Y LA SEGUNDA GUERRA MUNDIAL: LAS EMPRESAS EN UN CONTEXTO DE INCERTIDUMBRE, 1930-1950}

American \& Foreign Power comenzó a desarrollar su plan en 1929. Las empresas fueron reorganizadas en un grupo de cinco grandes compañías operativas: Compañía de Electricidad del Norte Argentino; Compañía de Electricidad del Sur Argentino; Compañía de Electricidad del Este Argentino; Compañía Central Argentina de Electricidad y Compañía de Electricidad de los Andes. Para la reconversión de las instalaciones hacia el sistema de corriente alterna, se aprobó un presupuesto de 7.500.000 dólares en 1930. La interconexión de las usinas y la organización de redes regionales produjeron un leve aumento de las ventas de electricidad de las subsidiarias de American \& Foreign Power. Pero los efectos de la crisis alteraron el desenvolvimiento del plan ${ }^{40}$.

La crisis del treinta determinó el cese de la expansión de las holdings eléctricas. La crisis financiera interrumpió el flujo de inversiones, el déficit de la balanza comercial interrumpió las importaciones de materiales e insumos y la transferencia de tecnología. La caída del sistema monetario basado en el patrón oro incrementó los costos por diferencias en el tipo de cambio, ocasionando la depreciación del capital de las compañías norteamericanas. Además, la devaluación de las monedas de los países receptores de la inversión y las restricciones a la salida de divisas determinaron la

\footnotetext{
40 American \& Foreign Power Company (1929, pp. 8-9).
} 
caída de los ingresos en moneda extranjera y la reinversión forzosa de las utilidades.

Los beneficios de las empresas de American \& Foreign Power en moneda extranjera cayeron alrededor del 18 por cien en 1931. Ante la interrupción del envío de divisas, los ingresos netos fueron reinvertidos. La compañía debió tomar nuevos préstamos de Electric Bond \& Share y renegociar los anteriores préstamos bancarios a interés más alto. Los ingresos se mantuvieron deprimidos hasta 1939. Entre 1933 y 1939, American \& Foreign Power no pagó dividendos, mantuvo la inversión al mínimo y aplicó los ingresos al pago de los intereses para reducir la deuda bancaria. Recién hacia 1940, se redujo el monto de las deudas y los intereses bajaron, las ganancias se incrementaron y las obligaciones disminuyeron, lo cual permitió reiniciar el pago de dividendos parciales del stock de las primeras acciones preferidas ${ }^{41}$.

El impacto de la crisis económica difirió según la localización de las subsidiarias de las compañías holdings. En las empresas que operaban en los países industrializados la recesión hizo caer el consumo de electricidad, afectando las ventas. En las economías no industrializadas, el problema principal fue la depreciación de las monedas y por ende, la caída de los ingresos en moneda extranjera. Entre 1928 y 1932, la producción de las empresas de SOFINA, por ejemplo, disminuyó en Francia, Bélgica, Alemania; se mantuvo en México, y aumentó sensiblemente en Argentina, España, Portugal y Turquía ${ }^{42}$.

Las diferencias por tipo de cambio motivaron la rápida acción de SOFINA, cuyas subsidiarias presionaron a los distintos gobiernos para ajustar las tarifas al nuevo tipo de cambio en aquellas concesiones que no hubieran previsto esta situación. Según las memorias de 1932, la mayoría de las concesiones preveían la revisión automática de tarifas por aumento del costo de la mano de obra, del precio del combustible y de las cargas fiscales, y por variaciones en la moneda. Cuando los poderes concedentes no llegaran a un acuerdo con las compañías, se recomendaba recurrir a autoridades independientes para gestionar la actualización tarifaria ${ }^{43}$.

Esta fue la estrategia aplicada por SOFINA en distintos países. En Argentina, la negociación para actualizar las tarifas de la CHADE sorteó la oposición de los concejales de la ciudad. Dannie Heineman se reunió con el jefe político del partido que tenía mayoría en el concejo deliberante porteño y, sobornos mediante, logró la renegociación del convenio, incluyendo una modificación de la estructura tarifaria que disponía la disminución del precio por kwh adicional consumido para promover el aumento del consumo por cliente. Al mismo tiempo, por causa de la guerra civil española,

${ }^{41}$ American \& Foreign Power (1932); United States. Securities and Exchange Commission (1947, pp. 12-14).

${ }^{42}$ SOFINA (1932, p. 28).

${ }^{43}$ SOFINA (1932, p. 17). 
SOFINA decidió tranferir los activos de CHADE a su subsidiaria argentina, la Compañía Argentina de Electricidad (CADE). La SER, por su parte, ajustó automáticamente las tarifas al tipo de cambio según lo estipulado en la concesión de Rosario ${ }^{44}$.

Los efectos de la crisis de 1930 dieron un nuevo valor a los términos de las concesiones. Durante la vigencia del sistema de patrón oro, la incidencia del tipo de cambio en las tarifas eléctricas no había generado dificultades para las compañías extranjeras. En la fase inicial de la electrificación, sólo las concesiones de las compañías inglesas estipulaban un ajuste automático de tarifas según el tipo de cambio. Las restantes empresas fijaron las tarifas en pesos moneda nacional, estableciendo un único mecanismo de regulación en la cláusula de progreso técnico según la cual, a partir de cierto porcentaje de decremento de los costos de producción, las tarifas debían disminuir. De modo que las empresas que adquirieron las concesiones de las compañías inglesas tuvieron una situación más favorable cuando aparecieron los problemas del tipo de cambio en los años treinta.

Por otra parte, la relativamente rápida recuperación de la economía argentina a partir de 1933 alentó el incremento del consumo a tasas superiores a las del crecimiento de la producción de electricidad. Entre 1931 y 1935, la producción de electricidad creció el 27,5 por cien y el consumo creció un 35,4 por cien. En 1936-1940, la brecha se amplió con tasas del 18,8 y 43,7 por cien respectivamente. El notable incremento de la demanda de electricidad resultó de la incorporación de nuevos clientes al sistema, que aumentaron de 1.094.000 a 1.505.940 en 1935-1940; así como del incremento del consumo industrial, que alcanzó el 56 por cien en el mismo período. Hacia 1940, el 44 por cien del consumo total correspondía a la demanda industrial; el 34 por cien, a la demanda residencial y comercial; 15 por cien correspondía al consumo del sector tranviario y un 7 por cien, para alumbrado público y entidades gubernamentales. En esta coyuntura, las ventas de electricidad, al igual que los beneficios en moneda argentina de las empresas de SOFINA, mantuvieron la tendencia creciente. Sólo durante el bienio 1931-1932, las empresas de SOFINA no registraron utilidades; a partir de 1933, generaron nuevamente utilidades aunque en un nivel inferior al de la década precedente ${ }^{45}$.

La naturaleza y evolución del mercado eléctrico en el área pampeana y las mejores condiciones relativas de las concesiones de las empresas de SOFINA, determinaron una evolución divergente a la experimentada por las empresas de American \& Foreign Power en los años treinta, con notables

${ }^{4}$ Un análisis de la estructura tarifaria de CATE, CHADE y CADE, en Bussola (2007).

45 Comisión Económica para América Latina (1956, pp. 121, 128); Argentina, Dirección General de Estadistica y censos de la Nacion (1941, pp. 327-330); SOFINA, S. A., Rapports, 1931 1940; Lanciotti (2008, p. 517). No se dispone de estadísticas oficiales que provean información sobre la estructura de la demanda de electricidad en Argentina para el período anterior a 1935. 
consecuencias en la década siguiente. Hemos señalado que las prioridades de la empresa norteamericana eran la renegociación de las concesiones, la reorganización financiera y el desarrollo de un plan de inversiones para ampliar y modernizar los sistemas, pero la crisis del treinta obstaculizó su concreción. Por un lado, la renegociación de las concesiones fue un proceso más arduo que el previsto por los directivos, y no tuvo resultados exitosos. La compañía había adquirido diecinueve compañías que operaban en ciento treinta comunidades, cada una de las cuales había acordado con diferentes autoridades diferentes términos en las concesiones. Pero además las concesiones adquiridas por el grupo venían operando desde hacía más de dos décadas, de modo que los contratos vencían en el lapso de una o dos décadas.

Después de 1930, las relaciones entre gobierno y empresas de servicios públicos se habían modificado. Los gobiernos presionaban por mantener tarifas reducidas, mientras que las empresas proponían ajustar las tarifas. La reorganización de las antiguas empresas en las cinco compañías mencionadas no alcanzó a las empresas que operaban en las ciudades más importantes del interior del país, Córdoba y Tucumán. Las concesiones de las empresas del grupo Herlitzka no habían estipulado cláusulas de ajuste por tipo de cambio, un factor clave en la negociación con las autoridades en un momento crítico. Estas empresas tampoco habían implementado las rebajas de tarifas acordadas con las autoridades, por lo que sus conflictos con los gobiernos provinciales se profundizaron. En los primeros años treinta, los gobiernos y las legislaturas provinciales de Córdoba y Tucumán crearon comisiones fiscalizadoras de los servicios eléctricos que reclamaron los compromisos incumplidos de inversión y la rebaja de las tarifas acordada con Herlitzka. En un contexto de nacionalismo creciente, las controversias se agudizaron y la renegociación de las concesiones fracasó.

También el desarrollo de planes de inversión para aumentar la eficiencia de los sistemas se vio obstaculizado por los efectos de la crisis del treinta. La caída de los ingresos de las compañías y la crítica situación en el mercado financiero estadounidense aumentaron los costos financieros y el endeudamiento de la empresa, limitando sus inversiones. Como hemos señalado antes, esta situación empezó a cambiar en 1940, pero entonces el conflicto bélico mundial atrajo nuevos problemas, especialmente la escasez de combustible. En un intento por recapitalizarse con recursos locales, la Compañía General de Electricidad de Córdoba emitió debentures y acciones preferidas por valor de $\$ 2.000 .000$ entre 1940 y 1942 . El aumento de los ingresos comenzaba a insinuarse cuando un golpe militar de corte nacionalista irrumpió en escena.

Las políticas dirigidas al sector tomaron una nueva dirección con el golpe militar de 1943. Durante más de medio siglo, la regulación del sector eléctrico se circunscribió a la fijación de tarifas máximas dispuesta según las concesiones otorgadas por autoridades de jurisdicción municipal o pro- 
vincial. A diferencia de lo sucedido en otros países latinoamericanos, el gobierno argentino no creó organismos fiscalizadores ni leyes para la industria eléctrica en los años treinta. La primera iniciativa del estado nacional fue la creación de Comisiones investigadoras de los servicios públicos de electricidad para revisar las concesiones. El gobierno tomó posesión de los libros en las oficinas de CIADE, CADE y de tres subsidiarias de American \& Foreign Power ${ }^{46}$.

El crecimiento de la demanda de electricidad se acentuó durante la segunda guerra mundial como consecuencia del aumento de la producción industrial y de la actividad económica en Argentina. Apenas finalizada la guerra, la limitada inversión y la obsolescencia tecnológica del sistema eléctrico, especialmente en las provincias del interior del país, profundizaron la insuficiencia de la oferta. Estos factores, combinados con la escasez de combustibles, determinaron que el déficit energético dejara de ser un problema coyuntural. Pero además, el desarrollo de la industria nacional fue un objetivo prioritario del gobierno militar, de modo que la crisis energética devino en un tema clave de la agenda estatal. En 1944, el gobierno declaró sujetos a expropiación los bienes de utilidad pública, y se creó la Dirección Nacional de la Energía, para regular la producción y distribución de energía, y promover el desarrollo de fuentes de energía no renovables. Complementariamente, en 1945 se creó la Dirección General de Centrales Eléctricas del Estado, dirigida a proyectar, ejecutar y explotar centrales y redes de distribución eléctrica ${ }^{47}$.

La política de expropiaciones llevada adelante entre 1943 y 1948 terminó por signar el destino de las empresas de American \& Foreign Power. Las expropiaciones se dirigieron especialmente a las subsidiarias norteamericanas por un conjunto de razones. Primero, porque este grupo de empresas había mantenido relaciones conflictivas con los gobiernos provinciales por el incumplimiento de lo acordado en las concesiones. Considerando que el plan de reestructuración de la compañía norteamericana había fracasado por las causas ya señaladas, el sistema continuaba operando por debajo de su capacidad. En consecuencia, desde los años treinta, la escasa extensión de las redes y el limitado aumento de la capacidad instalada consumaron la deficiente provisión del servicio y recurrentes cortes de energía.

En segundo lugar, American \& Foreign Power controlaba las empresas menos capitalizadas del país, cuyas concesiones estaban a punto de llegar a término, por lo que las compensaciones no representaban erogaciones de magnitud para el presupuesto estatal. Hacia 1946, el capital invertido por American \& Foreign Power en Argentina era de 274.044.980 pesos; mien-

${ }^{46}$ Decreto núm. 4.910, 6 de agosto de 1946, Archivo General de la Nación, Legajo 30, expediente 38876; Legajo 38, expediente 53003.

47 Decreto núm. 12.648 (1943), Decreto núm. 22.389 (1945); Argentina. Secretaría de Industria y Comercio (1946, p. 1). 
tras que la inversión de las empresas de SOFINA alcanzaba 1.067.131.445 pesos. En tercer lugar, las relaciones entre el gobierno norteamericano y el gobierno argentino se habían vuelto muy tensas desde 1941, cuando luego del desplazamiento del sector liberal del gobierno argentino a favor de grupos germanófilos, Estados Unidos inició un boicot comercial contra la Argentina ${ }^{48}$.

Un elemento adicional era que los directivos de las subsidiarias norteamericanas no tenían un acceso directo al gobierno, en contraste con los directivos de las empresas de SOFINA, algunos de cuyos asesores y gerentes fueron funcionarios del gobierno entre 1943 y 1955. Al momento de firmarse el decreto de expropiación, los directivos de SOFINA presionaron con éxito a funcionarios del gobierno para que intermediaran a favor de sus empresas frente al presidente Edelmiro Farrell.

En 1949, el 42 por cien de las propiedades de American \& Foreign Power había sido expropiado, mientras que las empresas no expropiadas eran deficitarias. En una coyuntura de aumento de costos por incrementos salariales y restricciones a la importación de materiales y maquinaria eléctrica, las subsidiarias de American \& Foreign Power en Argentina terminaron por desbarrancarse. La única opción era transferir las empresas al gobierno argentino, pero la crisis económica de 1949 dilató las negociaciones por más de una década. Finalmente, en 1956, los activos de las empresas argentinas se excluyeron de los informes de la compañía en función de la "prolongada experiencia insatisfactoria» en el país. Un breve balance cierra el episodio. El informe de la compañía expresaba que las empresas no recibían inversiones desde 1941 y que el déficit neto de las subsidiarias no expropiadas había ascendido desde 228.000 hasta 2.202.000 dólares en los últimos dos años. Entre 1930 y 1956, la ganancia promedio anual de American \& Foreign Power en Argentina fue menor al 1 por cien ${ }^{49}$.

Al evaluar el fracaso de las compañías de American \& Foreign Power, entre los factores internos a la empresa se destaca el limitado conocimiento del mercado argentino y de las compañías que operaban en el país. Entre 1927 y 1929, la compañía norteamericana pagó 117.000.000 dólares por las empresas en Argentina. Una nueva mirada al cuadro 1 muestra que el precio fue sobreestimado. Pero además, la mitad del capital de las compañías del grupo Herlitzka provenía de la emisión de debentures, de modo que las empresas tenían un elevado endeudamiento ${ }^{50}$.

En segundo lugar, las empresas del grupo tenían una larga trayectoria de conflictos por incumplimientos en el contrato y sus concesiones no tenían

48 Archivo General de la Nación, Fondo documental Secretaría de Asuntos Técnicos de la Nación 1946-1955, Legajo 395, 2. ${ }^{\circ}$ Plan Quinquenal, Plan de Energía Eléctrica (anexos). Escudé (1980, pp. 27-38).

49 American \& Foreign Power (1957, pp. 34-35).

50 American \& Foreign Power (1957, pp. 34-35). 
cláusulas de ajuste de tarifas. Como se ha señalado antes, durante las fases de expansión del sistema, los términos pactados en el convenio tuvieron una importancia relativa, en la medida que las condiciones del mercado argentino brindaron la posibilidad de obtener utilidades satisfactorias con moderada inversión. Pero el cambio de las condiciones en los años treinta, reveló la gran incidencia de las concesiones y de la experiencia en la relación con las autoridades en la capacidad de respuesta de las empresas en contexto de crisis. La estrategia de SOFINA de renegociar la estructura tarifaria para alentar el consumo, revelaba las mejores condiciones de las concesiones obtenidas, una gran capacidad de respuesta basada en el desarrollo previo de un sistema integrado a escala regional que podía cubrir el aumento de la demanda sin realizar inversiones, pero también revelaba la importancia de las relaciones que los directivos habían estructurado en el país a lo largo de su experiencia de negocios. Las empresas de American \& Foreign Power en Argentina carecían de los tres recursos mencionados. Particularmente, la ausencia de directivos bien relacionados con la esfera gubernamental se representa en la decisión de mantener a Herlitzka al frente de las compañías adquiridas, siendo que el citado era el blanco de las críticas de los usuarios y de los miembros de las comisiones investigadoras, que lo señalaban como el principal responsable de los incumplimientos contractuales en las décadas precedentes.

Un factor interno adicional que contribuye a explicar el fracaso de las empresas se relaciona con las elevadas expectativas de crecimiento del mercado latinoamericano desde la primera guerra mundial. Las alentadoras utilidades obtenidas por las empresas en Argentina, que había registrado los mayores índices de producción y consumo de electricidad de Latinoamérica hasta 1935, señala que la expectativa de beneficios estaba fundamentada en una clara tendencia previa. La visión optimista del futuro en una coyuntura de expansión del mercado norteamericano de títulos en los años veinte bien puede haber impulsado la decisión de adquirir compañías obsoletas a precios elevados.

Por cierto, la irrupción de la crisis de 1930 fue inesperada para los directivos de las compañías norteamericanas. Los señalados efectos de la crisis del treinta en el sector impactaron en forma radical sobre un sistema en vías de reorganización, y constituyó el principal factor externo que explica el fracaso de las empresas norteamericanas de electricidad. El advenimiento de la segunda guerra, la tardía emergencia del nacionalismo económico en la Argentina y las tensas relaciones comerciales entre los gobiernos de Argentina y los Estados Unidos terminaron por eliminar las escasas opciones de recapitalización de las empresas norteamericanas. 


\section{CONCLUSIONES}

Durante la fase inicial de electrificación, las empresas tuvieron una estructura de organización descentralizada y relativamente autónoma, representativa de un capitalismo de pequeña escala. La introducción de innovaciones tales como la implementación de la corriente alterna, la construcción de usinas de mayor tamaño, el reemplazo de máquinas de vapor por turbinas de vapor y la instalación de turbogeneradores y turboalternadores en la década previa a la primera guerra, impulsó el aumento de la producción y la extensión y reorganización de las redes para aprovechar los beneficios de las economías a escala. Este proceso generó una mayor demanda de capital de inversión, impulsando cambios en la gestión de las empresas con el fin de coordinar más eficientemente los recursos. Por esta razón, las compañías eléctricas iniciaron procesos de integración y coordinación jerárquica en consonancia con la expansión de la industria eléctrica y la reorganización de los sistemas bajo el control de compañías holding internacionales.

No todas las compañías acompañaron este proceso. Sobre la base del estilo de financiamiento y la disponibilidad de recursos gerenciales y técnicos, las free standing companies británicas siguieron dos variantes: transferir sus concesiones y activos a las empresas alemanas y belgas, o mantener sus empresas operando con baja tecnología y limitado capital antes de la primera guerra. En contextos de crecimiento económico, innovación tecnológica y expansión de la actividad, las estrategias conservadoras de las empresas y los comportamientos oportunistas de los agentes coexistieron con estilos de financiamiento y de operación más competitivos sin producir resultados sustantivamente diferentes en el corto plazo.

Puede establecerse que el ciclo de vida de las compañías autónomas inglesas fue breve en relación con la trayectoria de las empresas controladas por las multinacionales y holdings europeas. Esta observación concuerda con lo señalado por Casson respecto a que aquellas sociedades evitaron su reorganización minimizando los costos de transacción en el corto plazo, pero que la situación no podía persistir en las industrias más progresivas tecnológicamente, como la industria eléctrica. Ahora bien, fueron estrategias de corto plazo pero no fueron estrategias fallidas. Las free standing companies inglesas que operaban en este sector no fracasaron en la medida en que su objetivo no consistió en expandirse y controlar el sector, sino obtener ingresos sobre la base de las ventajas adquiridas en industrias relacionadas con la propiedad. Desde el punto de vista del rendimiento del capital, sus trayectorias tampoco pueden evaluarse negativamente, puesto que una vez resueltos los problemas de agencia y acordados términos convenientes con las autoridades, las empresas obtuvieron utilidades equivalentes a las obtenidas en otras actividades, valorizaron sus activos y obtuvieron significativas diferencias al momento de la venta. Las ventajas derivadas de 
la propiedad de activos específicos sostuvieron la valorización de las empresas que habían estabilizado su gestión financiera.

Durante la expansión de los años veinte, las empresas inglesas y las empresas del grupo Herlitzka continuaron operando y generando márgenes de utilidad aceptables sin modificar pautas de inversión ni estilos de financiamiento. Tampoco en ese momento se registraron fracasos evidentes, pero sí un mayor nivel de endeudamiento y una ampliación de la brecha en el nivel de utilidades obtenidas por las empresas de baja capitalización/tecnología y las empresas que desarrollaron sistemas tendientes a maximizar los beneficios de las economías a escala.

Los problemas derivados de los contratos incompletos, la desinversión y la escasa expansión de las empresas que operaban en las provincias argentinas se tornaron visibles en las condiciones generadas por la crisis, cuando las empresas ya habían sido vendidas a American \& Foreign Power. La compañía norteamericana contaba con recursos técnicos y financieros para desarrollar sistemas competitivos en un contexto de elevadas barreras de entrada al sector, pero la irrupción de la crisis impidió la plena utilización de esos recursos. Durante los años treinta, se detuvo el desarrollo, y persistieron los artefactos y las características ya adquiridas. En esta fase, fueron las capacidades internalizadas las que marcaron la diferente respuesta de las empresas, y por ende su diferente desempeño.

El desempeño en las coyunturas de crisis actualizó los patrones evolutivos de las empresas definidos en las fases previas de crecimiento e innovación. Como consecuencia de la crisis de 1930, las diferencias en el tipo de cambio, la depreciación de los activos y la caída de los ingresos a la par que la actualización de los conflictos entre las empresas y los usuarios, pusieron de manifiesto que las heterogéneas condiciones de contratación de los servicios produjeron diferencias significativas en la definición de los derechos de propiedad de las empresas inglesas, belgas y norteamericanas.

Se establece entonces que no toda la experiencia internalizada por las empresas representaba un capital intangible valioso para adaptarse a las condiciones cambiantes de los mercados. Los patrones de evolución económica y tecnológica, los derechos de propiedad acordados y la experiencia de negocios en la región configuraron las opciones posibles para cada grupo de empresas. Para las empresas controladas por SOFINA y por Motor Columbus-SSAE, esto representó mayores recursos en la negociación con las autoridades locales. Los mismos factores limitaron las opciones del grupo norteamericano. Cuando American \& Foreign Power adquirió las compañías británicas y las empresas del grupo Herlitzka, se hizo cargo de un importante pasivo representado por la experiencia negativa acumulada durante la gestión previa, concesiones incumplidas e instalaciones obsoletas. La internalización de los conflictos y la inercia organizacional de las antiguas compañías complicó aún más la capacidad de respuesta frente al cambio en las condiciones políticas y económicas en una fase de estabilización de la tecnología. 


\section{FUENTES}

American \& Foreign Power Company Inc.: Annual Reports, 1924-1958.

Anuario Pillado de la deuda pública y sociedades anónimas establecidas en la República Argentina. Buenos Aires, 1899.

Argentina, Dirección General de Estadística y Censos de la Nación (1944): Estadística Industrial de 1941. Buenos Aires.

Argentina. Secretaría de Industria y Comercio. Dirección Nacional de la Energía (1946): Memoria de la Dirección General de Centrales Eléctricas del Estado, correspondiente al año 1946. Buenos Aires, 1946.

Archivo General de la Nación (AGN). Buenos Aires: Fondo documental Secretaría de Asuntos Técnicos de la Nación 1946-1955, Legajo 395, 2. ${ }^{\circ}$ Plan Quinquenal, Plan de Energía Eléctrica.

Compañía Alemana Transatlántica de Electricidad (DUEG) (1910): La Compañía Alemana Transatlántica de Electricidad en razón del primer centenario de la independencia de la República Argentina. Berlín.

- Informe Anual, 1906-1919.

Compañía Argentina de Electricidad: Memoria y Balance General, 1936-1938. Buenos Aires.

- Rapport pour l'exercise, 1920-1938. Bruxelles.

- (1927): Las usinas de la CHADE. Estado de las instalaciones al 31 de diciembre de 1927. Buenos Aires: Publicación de la empresa.

Compañía Italo Argentina de Electricidad (1930): La Compañía Italo Argentina de Electricidad. Buenos Aires: Publicación de la empresa.

- (1931): Evolución y desarrollo de la Compañía Italo Argentina de Electricidad en los primeros veinte años de su actividad. Buenos Aires.

Monitor de Sociedades Anónimas, 1903-1933, Javier Padilla (dir.). Buenos Aires: Imprenta y Casa Editora de Coni Hermanos.

Municipalidad De Rosario (1946): Informe de la Comisión Municipal Fiscalizadora de la Sociedad de Electricidad de Rosario. Rosario: Tipografía Llordén.

Revista Electrotécnica. Publicación de la Asociación Argentina de Electrotécnicos, Buenos Aires, años 1928-1938.

Société Financière de Transports et D'ENTREPRises Industrielles (SOFINA, S. A.): Rapport du conseil d'administration a l'assemblée générale ordinaire des actionnaires, Rapport du college des commissaries. Exercises 1926-1950, Bruxelles.

- Prospectus. 22 enero 1929.

- (1930): «Sofina's participations in Public Utility Companies». New York, unpaged.

Société SuIsse-AmeriCAINE D’Electricité: Annual reports. 1929-1932, 1934-1938.

The Argentine Year's Book. 1903-1916. London-Buenos Aires: Robert Grant \& Co.

United States. Securities and Exchange Commission (1947): «Holding Company Act 1935». Findings and Opinion of the Commission in the matter of American \& Foreign Power Company Inc. Electric Bond \& Share Company File núm. 7815. Philadelphia.

- (1952): "The Public Utility Holding company Act of 1935». Report to the Subcommittee on Monopoly of the Select Committee on Small Business. Washington. 


\section{BIBLIOGRAFÍA}

BARbero, M. (1990): «Grupos empresarios, intercambio comercial e inversiones italianas en la Argentina. El caso de Pirelli (1910-1920)». Estudios Migratorios Latinoamericanos, 15-16, pp. 267-340.

- (2004): «Impacto de la inversión extranjera directa en la industria argentina en la década de 1920. Estrategias empresariales y sus efectos sobre el sector productivo local». Revista do Centro de Estudos Interdisciplinares do Século XX, 4, pp. 201-222.

Brion, R., y MOREAU, J. L. (2001): Inventaire des archives du groupe SOFINA (Société Financière de Transports et d'Entreprises Industrielles) 1881-1988. Bruxelles: Archives générales du Royaume.

Bussola, D. (2007): «La regulación de la electricidad en la ciudad de Buenos Aires. El caso CATE/CHADE/CADE (1908-1958)». [CD] XI Jornadas Interescuelas/Departamentos de Historia, Tucumán: UNT.

COMISIÓN ECONÓMiCA PARA AMÉRICA LATINa (1956): La energía en América Latina. México: Naciones Unidas.

Casson, M. (1994): «Institutional Diversity in Overseas Enterprise: Explaining the FreeStanding Company». Business History, 36 (4), pp. 95-108.

Corley, T. A. B. (1994): «Britain's Overseas Investments in 1914 Revisited». Business History, 36 (1), pp. 71-88.

Fridenson, P. (2004): "Business Failure and the Agenda of Business History». Enterprise \& Society, 5 (4), pp. 562-582.

Escude, C. (1980): «Las Restricciones Internacionales de la Economía Argentina 19451949». Desarrollo Económico, 77, pp. 3-40.

García Heras, R. (1994): Transporte, negocios y política. La Compañía Anglo Argentina de Tranvías. 1876-1981. Buenos Aires: Sudamericana.

HASSAN, J. (1995): «The water industry 1900-1951; a failure of public policy?», en R. Millward y J. Singleton, The Political Economy of Nationalisation in Britain, 19201950. Cambridge: CUP, pp. 189-211.

Hausman, W., y Neufeld, J. (1997): "The rise and fall of American \& Foreign Power Company. A lesson from the past?». The Electricity Journal, 10, pp. 46-53.

Hausman, W.; Hertner, P., y WiLkins, M. (2008): Global Electrification. Multinational Enterprise and International Finance in the History of Light and Power, 1878-2007. New York: Cambridge University Press.

Hennart, J. F. (1994): «International Financial Capital Transfers: A Transaction Cost Framework». Business History, 36 (1), pp. 51-70.

Hertner, P. (1986): «German Multi-National Enterprise before 1914: Some Case Studies», en P. Hertner y G. Jones, Multinationals: Theory and History. Aldershot: Gower, pp. 113-132.

Hertner, P., y Nelles, H. V. (2007): «Contrasting Styles of Foreign Investment. A Comparison of the Entrepreneurship, Technology and Finance of German and Canadian Enterprises in Barcelona Electrification». Revue économique, 58 (1), pp. 191-214.

Hughes, Th. P. (1989): «The evolution of Large Technological Systems», en W. BiJKER, Th. P. Hughes and T. PINch (eds.), The Social Construction of Technological Systems: New directions in the Sociology and History of Technology. Cambridge: MIT Press, pp. 51-83.

Jones, Ch. (1973): «British Financial Institutions in Argentina, 1860-1914». Ph D. Dissertation. Cambridge: University of Cambridge (unpublished).

- (1995): «Los antecedentes de la moderna corporación transnacional: los grupos de inversión británicos en América Latina», en C. MARICHAL (comp.), Las inversiones 
extranjeras en América Latina, 1850-1930. México: Fondo de Cultura Económica, pp. 70-95.

Jones, Ch.; Jones, L., and GreenhiLl, R.(1977): «Public Utility Compañies», en D. C. M. Platt (ed.), Business Imperialism 1840-1930. An inquiry based on British experience in Latin America. Oxford: Oxford University Press, pp. 77-118.

Jones, G. (2000): Merchants to Multinationals. Oxford: Oxford University Press.

LANCIOTTI, N. (2007): «Empresas autónomas y Grupos de inversión. Las empresas del Grupo Morrison en Rosario, Argentina (1890-1960)». Investigaciones de Historia Económica, 3 (8), pp. 503-528.

- (2008): "Foreign Investments in Electric Utilities: A Comparative Analysis of Belgian and American Companies in Argentina, 1890-1959». Business History Review, 82 (3), en prensa.

- (2008b): «Estrategias de inversión, cambio tecnológico y rentabilidad de las empresas de electricidad en Argentina. La Sociedad de Electricidad de Rosario, 19101956». Anuario IEHS, 23, en prensa.

LLUCH, A. (2007): «La inversión extranjera directa norteamericana en Argentina (19001930)», ponencia presentada a V Coloquio sobre Historia de Empresas. Buenos Aires: Universidad de San Andrés, marzo de 2007.

MARTínez LóPEZ, A. (2003): «Belgian investment in tramways and light railways: an international approach, 1892-1935». The Journal of Transport History, 24, pp. 59-77.

Miller, R. (1998): "British Free-Standing Companies on the West Coast of South America», en M. WiLKIns y H. Schroter, The Free-Standing Company in the World Economy, 1830-1996. New York: Oxford University Press, pp. 218-252.

Moss, M., y JoberT, Ph. (eds.) (1995): Naissance et mort des entreprises en Europe XIXeXXe siècles. Dijon: Éditions de l'Université de Dijon.

RegalsKy, A (2001): "¿Una experiencia de banca industrial en la Argentina agroexportadora? El Banco Francés del Río de la Plata, 1905-1914». Anuario del Centro de Estudios Históricos Prof. C. S. Segretti, 1, pp. 215-239.

Regalsky, A., y SALERNo, E. (2008): «En los comienzos de la empresa pública argentina: la Administración de los Ferrocarriles del Estado y las Obras Sanitarias de la Nación antes de 1930». Investigaciones de Historia Económica 11, pp. 107-136.

SEgRETO, L. (1994): «Financing the Electric Industry World-wide: Strategy and Structure of the Swiss Electric Holding Companies, 1895-1945». Business and Economic History, 23, pp. 163-168.

SOLVEIRA, B. (2006): "Objetivos y estrategias de producción de las principales empresas eléctricas de la provincia de Córdoba, 1893-1946)», [CD] XX Jornadas de Historia Económica. Mar del Plata: AAHE.

- (2007): «Relación Estado-empresas de electricidad en la provincia de Córdoba, durante la primera mitad del siglo XX», en J. SchVARZER, T. GómEZ y M. RougIER (comps.), La empresa ayer y hoy. Nuevas investigaciones y debates. Buenos Aires: CESPA.

WiLKINS, M. (1974): The maturing of multinational enterprise: American business abroad from 1914 to 1970 . Cambridge: Harvard University Press.

- (1988): "The Free-Standing Company, 1870-1914: An Important Type of British Foreign Direct Investment». Economic History Review, 41 (2), pp. 259-282.

- (1994): «Comparative Hosts». Business History, 6 (1), pp. 18-50.

- (1998): «The Free Standing Company revisited», en M. WiLkins y H. Schroter, The Free-Standing Company in the World Economy, 1830-1996, New York: Oxford University Press, pp. 3-61.

YounG, G. (1991): "British Overseas Banking in Latin America and the Encroachment of German Competition, 1887-1914». Albion: Quarterly Journal Concerned with British Studies, 23 (1), pp. 75-99. 